\title{
Perspective
}

\section{Nature's Machinery, Repurposed: Expanding the Repertoire of Iron-Dependent Oxygenases}

Noah P. Dunham, and Frances H. Arnold

ACS Catal., Just Accepted Manuscript • DOI: 10.1021/acscatal.0c03606 • Publication Date (Web): 28 Sep 2020

Downloaded from pubs.acs.org on September 29, 2020

\section{Just Accepted}

"Just Accepted" manuscripts have been peer-reviewed and accepted for publication. They are posted online prior to technical editing, formatting for publication and author proofing. The American Chemical Society provides "Just Accepted" as a service to the research community to expedite the dissemination of scientific material as soon as possible after acceptance. "Just Accepted" manuscripts appear in full in PDF format accompanied by an HTML abstract. "Just Accepted" manuscripts have been fully peer reviewed, but should not be considered the official version of record. They are citable by the Digital Object Identifier (DOI®). "Just Accepted" is an optional service offered to authors. Therefore, the "Just Accepted" Web site may not include all articles that will be published in the journal. After a manuscript is technically edited and formatted, it will be removed from the "Just Accepted" Web site and published as an ASAP article. Note that technical editing may introduce minor changes to the manuscript text and/or graphics which could affect content, and all legal disclaimers and ethical guidelines that apply to the journal pertain. ACS cannot be held responsible for errors or consequences arising from the use of information contained in these "Just Accepted" manuscripts. 


\title{
Nature's Machinery, Repurposed: Expanding the Repertoire of Iron-Dependent Oxygenases
}

\author{
Noah P. Dunham and Frances H. Arnold* \\ Division of Chemistry and Chemical Engineering, California Institute of Technology, 1200 East \\ California Boulevard, MC 210-41, Pasadena, California 91125, United States
}

\begin{abstract}
Iron is an especially important redox-active cofactor in biology because of its ability to mediate reactions with atmospheric $\mathrm{O}_{2}$. Iron-dependent oxygenases exploit this earthabundant transition metal for the insertion of oxygen atoms into organic compounds. Throughout the astounding diversity of transformations catalyzed by these enzymes, the protein framework directs reactive intermediates toward the precise formation of products, which, in many cases, necessitates the cleavage of strong $\mathrm{C}-\mathrm{H}$ bonds. In recent years, members of several iron-dependent oxygenase families have been engineered for new-to-nature transformations that offer advantages over conventional synthetic methods. In this Perspective, we first explore what is known about the reactivity of heme-dependent cytochrome P450 oxygenases and nonheme iron-dependent oxygenases bearing the 2-His-1-carboxylate facial triad by reviewing mechanistic studies with an emphasis on how the protein scaffold maximizes the catalytic potential of the iron-heme and iron cofactors. We then review how these cofactors have been repurposed for abiological transformations by engineering the protein frameworks of these enzymes. Finally, we discuss contemporary challenges associated with engineering these platforms and comment on their roles in biocatalysis moving forward.
\end{abstract}

KEYWORDS: biocatalysis, enzymology, directed evolution, mechanism, oxygenase, cytochrome $P 450$ 


\section{INTRODUCTION}

Nature's finest catalytic machinery is comprised of protein-based enzymes. Constructed mainly of polypeptide chains of the twenty genetically encoded amino acids, enzymes can assume a multiplicity of three-dimensional forms, which is the foundation for the remarkable diversity of chemical transformations that are catalyzed with the efficiency and selectivity required to support a living organism. ${ }^{1}$ While a great deal of this catalysis can be achieved within the manifold of functional groups provided by the canonical proteinogenic amino acids, whether by simple acidbase reactions or through intermediary covalent linkages, many essential biochemical transformations necessitate catalytic capabilities that exceed what is offered by these residues. The solution comes in the form of metallic or organic cofactors, with which many proteins are equipped to expand their catalytic repertoires. In this context, the interplay between the protein and cofactor is crucially important: the acquired catalytic function stemming from the unique properties of the cofactor is elicited or amplified by the protein environment. Cofactor-protein complexes achieve levels of activity and chemo-, regio-, and stereoselectivity that far surpass that which is produced by either component separately.

Since the emergence of our aerobic atmosphere, redox-active metals have taken on additional functions. Because the direct reaction of molecular oxygen $\left(\mathrm{O}_{2}\right)$ in its thermodynamically favored triplet ground state with singlet organic compounds is generally spinforbidden, metallocofactors with unpaired $d$-electrons, such as iron, provide a channel to mediate such reactions by reductive activation of this atmospherically prevalent molecule. ${ }^{2-4}$ The resulting metal-oxygen species serve as intermediates in pathways that are central to biology, Complex IV of the electron transport chain in aerobic respiration perhaps being the most notable example. Many other metalloenzymes activate $\mathrm{O}_{2}$ to insert oxygen atoms into the structures of their organic 
substrates. ${ }^{5}$ These oxygenases have provided us with powerful catalysts for biosynthesis and synthetic chemistry.

In this Perspective, we discuss the role of iron both in the heme complex and as free ferrous ion, and how its catalytic potential is maximized by proteins to effect oxygenase reactions. Toward this goal, we recount the catalytic cycles of heme-dependent cytochromes P450 and nonheme irondependent oxygenases that utilize the 2-His-1-carboxylate facial triad, highlighting throughout how the protein sequence imparts selective catalysis. The knowledge accumulated from decades of rigorous mechanistic studies demonstrates the advantages of using an enzyme to achieve such outcomes, especially in cases where direct comparison can be made to the reactivity of the proteinfree cofactor.

From this foundational understanding of how Nature's catalytic machinery controls reactivity and specific product outcomes, we bring the discussion to contemporary challenges in chemical synthesis by showing how the catalytic capabilities of natural enzymes can lead to discovery and optimization of new-to-nature transformations. Leveraging enzymes for the synthesis of high-value chemicals constitutes a powerful strategy with broad potential. ${ }^{6}$ While natural evolution has sharpened the myriad native functions of enzymes for specific biological advantages, it would be imprudent to look upon these functions as limits of achievability. Applying directed evolution, it is now feasible, even uncomplicated, to enhance the latent activities of enzymes for non-natural chemistry and further expand our synthetic toolbox, ${ }^{7}$ just as Nature has expanded hers over millions of years. In other words, the well of innovation is just waiting to be tapped. Recently, a number of iron-dependent oxygenases have been engineered to realize such a goal. Herein, we summarize the efforts of several research groups to push the hemoprotein and 
nonheme 2-His-1-carboxylate enzymatic platforms into the world of abiological catalysis, and then speculate on the future impact on chemical synthesis.

Eliciting new reactivity from cofactor-dependent enzymes and honing this reactivity by directed evolution is truly at the interface between enzymology and synthetic chemistry. Inspiration drawn from both fields can contribute to transformational advancements in our ability to craft molecules using biocatalysts. While the focus of this Perspective is narrowed to irondependent oxygenases, our broader goal is to inspire researchers to examine existing biological cofactors as potential sources of new and useful chemistry, from which fundamental knowledge stands to be extracted and new synthetic tools stand to be developed.

\section{HEME}

\subsection{Structure and Reactivity}

Heme cofactors employ the organic porphyrin framework to coordinate iron for a diversity of functions. ${ }^{8}$ The $18 \pi$ electrons of the core structure (Figure 1, red substructure), which consists of four pyrrole subunits connected by methine bridges, are thought to be the basis of the cofactor's aromatic character, ${ }^{9}$ the key contributor to its absorption properties and the generation of $\pi$-cation radicals during the formation of high-valent iron intermediates. ${ }^{10}$ The resulting planar structure coordinates the iron in a tetradentate fashion and occupies an entire plane of the octahedron. One or both coordination sites perpendicular to this equatorial plane can be occupied by additional axial ligands (X in Figure 1), which often play a crucial role in tuning the electronic properties of the metal (vide infra). ${ }^{11}$ In the active site of an enzyme, these ligands are contributed by amino acid side-chains. 
Heme's impressive catalytic repertoire is evident throughout its assortment of biological functions. From oxygen maintenance ${ }^{12,13}$ and electron transfer ${ }^{14}$ to decomposition of harmful oxygen species ${ }^{15,16}$ and facilitating an array of chemically challenging oxidative transformations, ${ }^{17-21}$ Nature has given this special cofactor a starring role. Heme has also been an inspiration to chemists for decades. Their efforts have not only yielded model complexes that elevated our understanding of hemoproteins, but also afforded a collection of biomimetic catalysts that have addressed a number of synthetic challenges.

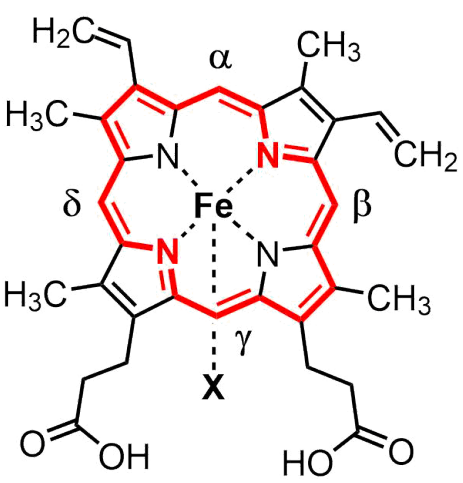

Figure 1. Structure of heme B. The bolded red bonds constitute the $18 \pi$ electrons of the aromatic system in the [18]annulene model. $\mathbf{X}$ represents the axially coordinated protein ligand.

These synthetic porphyrins have been extensively reviewed elsewhere. ${ }^{19,22-26}$

Although Nature and humanity together have leveled a great deal of attention on heme, the natural forms of the cofactor by itself have found very limited use in biology as well as industrial pursuits. Thus, the question must be asked: how does the hemoprotein environment tune the cofactor such that the desired reactivity is achieved? Here we strive to answer this question in the context of cytochromes P450, the family of hemoproteins that have been described as 'a biological blowtorch' ${ }^{27}$ These enzymes catalyze a suite of aliphatic and aromatic C-H oxidations, ${ }^{28,29}$ heteroatom oxidations, ${ }^{30,31}$ olefin epoxidations, ${ }^{32} \mathrm{C}-\mathrm{C}$ desaturations, ${ }^{33,34}$ and more, ${ }^{18,35}$ rendering them an ideal subject for a case study on how the polypeptide chain can activate and tune the heme cofactor for highly selective transformations that are not observed in the absence of the protein scaffold.

\subsection{C-H Hydroxylation Catalyzed by Cytochromes P450}


Cytochromes P450 — named for the $450 \mathrm{~nm}$ absorption band observed with the reduced, CO-bound state of the heme B cofactor ${ }^{36}$ — are found throughout every kingdom of life. ${ }^{37} \mathrm{P} 450$ s coordinate one of the two axial sites of the iron center with a cysteine ligand, leaving the other open for binding of water or $\mathrm{O}_{2}$. In the hydroxylation reaction, the net four-electron reduction of $\mathrm{O}_{2}$ is balanced by the two-electron oxidations of both $\mathrm{NAD}(\mathrm{P}) \mathrm{H}$ and the aliphatic $\mathrm{C}-\mathrm{H}$ bond undergoing oxygenation (Equation 1). ${ }^{18}$ Amazingly, the bond dissociation energies (BDE) of the targeted C$\mathrm{H}$ bonds can range as high as $102.9 \mathrm{kcal} / \mathrm{mol},{ }^{38}$ an energy barrier that is overcome by reactive highvalent iron-oxo intermediates. Throughout the step-by-step mechanism presented below, we highlight the role of the protein scaffold and its contributing ligands in facilitating the formation and directing the reactivity of these reactive intermediates.

$$
\mathrm{RH}+\mathrm{O}_{2}+\mathrm{NAD}(\mathrm{P}) \mathrm{H}+\mathrm{H}^{+} \rightarrow \mathrm{ROH}+\mathrm{H}_{2} \mathrm{O}+\mathrm{NAD}(\mathrm{P})^{+}
$$

In the resting state of the $\mathrm{P} 450$ active site, a water ligand occupies the sixth coordination site of the low-spin $(S=1 / 2) \mathrm{Fe}(\mathrm{III})$ cofactor (Figure 2, state I). ${ }^{11,18,39}$ Binding of the substrate then displaces this axially coordinated water, which is important for two main reasons: (1) an axial coordination site is now open for binding of $\mathrm{O}_{2}$, and (2) the change in the coordination environment shifts the iron to a high-spin $(S=5 / 2)$ state (state II). ${ }^{11,18}$ The latter consequence brings the redox potential of the iron into the range of the corresponding cytochrome P450 reductase, which then delivers an electron originating from $\mathrm{NAD}(\mathrm{P}) \mathrm{H}$ through the reduced form of its flavin mononucleotide $(\mathrm{FMN})$ cofactor. ${ }^{40-42}$ The coupling of this protein-controlled substrate binding event with the reorganization of the ligand sphere effectively prevents entrance into the catalytic cycle in the absence of substrate. It is worthy of note that while this substrate-induced spin-shift strategy is a classic example of the control of electron flow in P450 catalysis, it is not universally employed within the family. Alternative mechanisms have been reviewed elsewhere. ${ }^{43}$ 
Reduction of the heme to $\mathrm{Fe}$ (II) triggers binding and reduction of $\mathrm{O}_{2}$ to yield a ferric superoxo species (Figure 2, state IV), an intermediate that, if neglected, will produce harmful reactive oxygen species (ROS). ${ }^{44}$ Thus, efficient delivery of a second electron and a proton are required at this stage to push the reaction forward toward the formation of the ferric hydroperoxo intermediate known as compound 0 (state VI). ${ }^{45}$ This sequence, in addition to the initial reduction of the cofactor, necessitates precisely controlled access of the partner P450 reductase to the P450

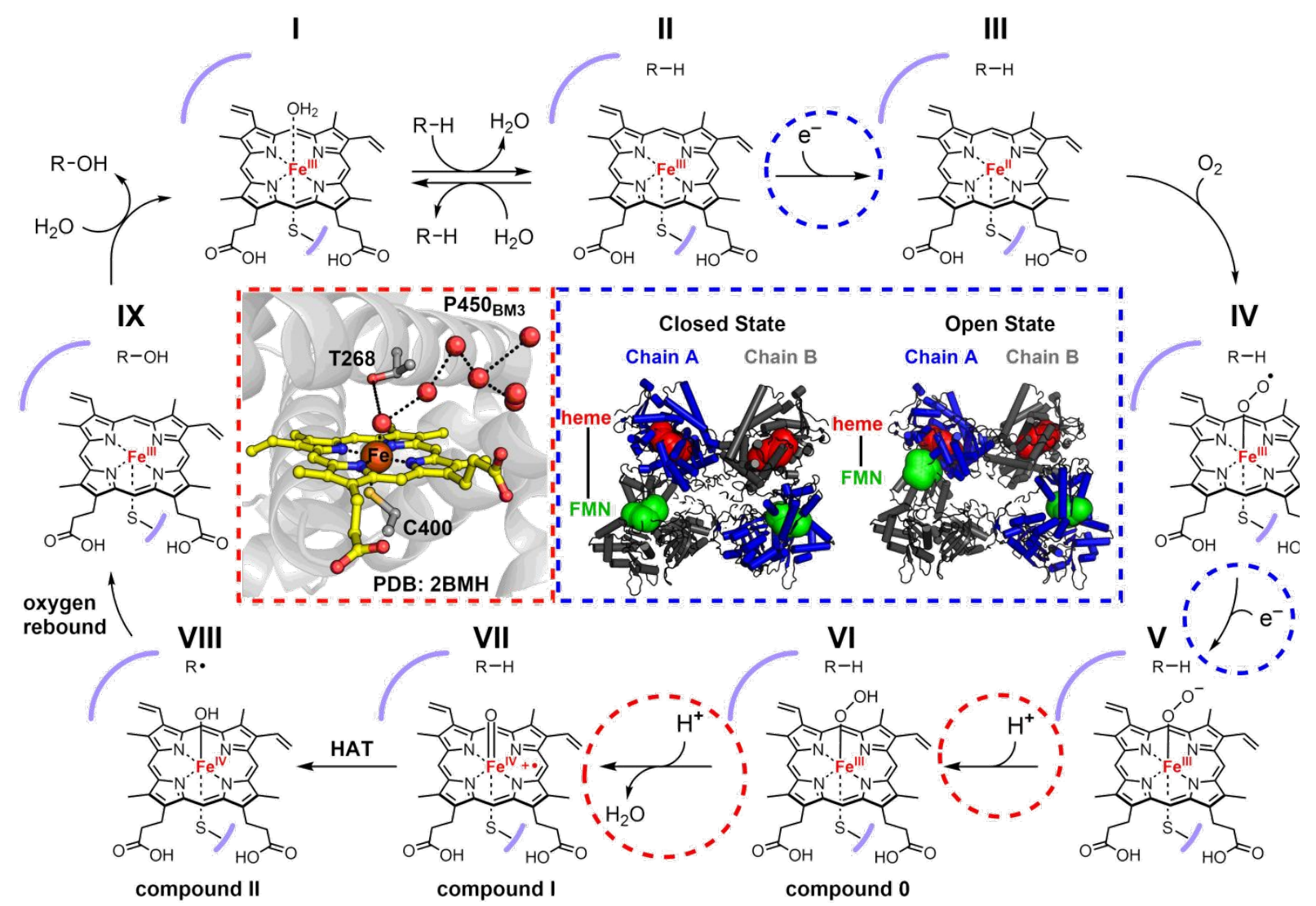

Figure 2. Mechanism of P450-catalyzed hydroxylation. The red inset (left) depicts the active site of the $\mathrm{P} 450_{\mathrm{BM} 3}$ heme domain in the substrate-free crystal structure (PDB: 2BMH). The conserved T268 residue sits directly above the heme, in close contact with an ordered water network (red spheres) for the proton-transfer steps. The blue inset (right) shows the conformational shift between the closed and open states of the full-length $\mathrm{P} 40_{\mathrm{BM} 3}$ dimeric complex (models derived from cryo-EM maps EMD: 20785 and EMD: 20786), which brings the heme (red spheres) from one monomer and FMN (green spheres) from the other in close proximity for the electron transfer steps. 
active site. Complementing the years of rigorous explorations into this process ${ }^{46}$ the recently solved single-particle cryo-EM structure of the full-length cytochrome P450 from Bacillus megaterium ( $\mathrm{P} 450_{\mathrm{BM} 3}$ ), a self-sufficient $\mathrm{P} 450$ with the partner reductase fused into a single polypeptide chain, is an excellent model of how such control can be imparted by the protein framework. ${ }^{47}$ This structure provides a clear picture of how the dimeric complex can exist in open and closed states, and how a conformational shift to the former brings the FMN cofactor of one monomer into close proximity with the heme of the other, presenting a mechanism by which electrons can be delivered to the cofactor in a manner controlled at the quaternary level of the protein structure (blue inset). Meanwhile, a conserved threonine residue (T268 in P450 $0_{\mathrm{BM} 3}$ ) positioned above the heme likely facilitates the proton transfer either by direct interaction with distal oxygen of the ferric peroxo intermediate (state $\mathbf{V}$ ), or by extending its access to a nearby water network (red inset). ${ }^{48-50}$

This conserved threonine residue also plays a crucial role in the subsequent $\mathrm{O}-\mathrm{O}$ bond scission step by assisting the delivery of a second proton to the distal oxygen of compound 0 (Figure 2, red inset), which results in release of water and formation of compound I (state VII). Mutation of this threonine residue to alanine in either $\mathrm{P} 450_{\mathrm{BM} 3}$ or $\mathrm{P} 450_{\mathrm{CAM}}$ diminished hydroxylation activity and increased production of $\mathrm{H}_{2} \mathrm{O}_{2} \cdot{ }^{48,49}$ The uncoupling of $\mathrm{O}_{2}$ reduction from substrate oxidation highlights the importance of precision proton delivery for efficient $\mathrm{O}-\mathrm{O}$ bond scission. Moreover, a recent study showed that a glutamic acid substitution allowed these P450s to operate as peroxygenases, whereby substrate oxidation could be achieved through the peroxide shunt pathway. ${ }^{51}$ These "pull" effects are complemented by the "push" effect exerted by the axial cysteine ligand: the strong $\sigma$-donation from the thiolate, which effectively drives electron density into the antibonding $\mathrm{O}-\mathrm{O}$ orbital, also contributes to productive $\mathrm{O}-\mathrm{O}$ bond heterolysis. ${ }^{11,19,52}$ 
The two additional electrons required for reduction of hydrogen peroxide to water and $\mathrm{O}-$ $\mathrm{O}$ bond scission are afforded by the iron and the organic porphyrin scaffold, resulting in the formation of the high-valent $\mathrm{Fe}(\mathrm{IV})$-oxo (ferryl) $\pi$-cation radical species known as compound I (Figure 2, state VII). ${ }^{10,53}$ This potent oxidant intermediate facilitates hydrogen atom transfer (HAT) from the substrate $\mathrm{C}-\mathrm{H}$ bond to the cofactor, generating the $\mathrm{Fe}(\mathrm{IV})$-hydroxide species known as compound II and a substrate radical (state VIII). ${ }^{54}$ The reaction cycle is completed by transfer of the oxygen ligand to the carbon-centered radical (termed oxygen rebound, state VIII to IX), ${ }^{55}$ release of the hydroxylated product, and then rebinding of the water, returning the cofactor to its resting state ( state $\mathbf{I X}$ to $\mathbf{I}){ }^{18}$

During this sequence, P450s exhibit exquisite control over highly reactive intermediates (e.g., compound I) to achieve productive cleavage of the substrate $\mathrm{C}-\mathrm{H}$ bond while preventing the oxidation of readily oxidizable amino acids within its own framework, such as tyrosines and tryptophans. The axial cysteine ligand was initially posited to play a crucial role in the prevention of such undesired reactions because it is present in all P450s and chloroperoxidase (CPO) ${ }^{11}$ the members of the hemoprotein family known to cleave strong $\mathrm{C}-\mathrm{H}$ bonds. Green, Dawson, and Gray postulated the difference in free energy between the productive $\mathrm{C}-\mathrm{H}$ activation pathway and nonproductive tyrosine oxidation pathway was largely dependent on the $\mathrm{p} K_{\mathrm{a}}$ of the resulting compound II, which was increased by the strong electron donation from the thiolate ligand ${ }^{56,57}$ In 2013, Green and coworkers validated this hypothesis by trapping and characterizing compound II of Streptomyces coelicolor CYP158 at differing $\mathrm{pH}$ values, determining its $\mathrm{p} K_{\mathrm{a}}$ to be nearly 12 (more than 8 orders of magnitude more basic than the histidine-ligated heme peroxidases). ${ }^{54,56}$ This change in axial ligand from histidine to cysteine alters the thermodynamic favorability of tyrosine oxidation (via uncoupled proton and electron transfer) over substrate $\mathrm{C}-\mathrm{H}$ bond cleavage (via 
HAT) from $\sim 14 \mathrm{kcal} / \mathrm{mol}$ to only $3 \mathrm{kcal} / \mathrm{mol}$, bringing the $\mathrm{P} 450$-catalyzed $\mathrm{C}-\mathrm{H}$ oxidation reaction into the range of kinetic control..$^{54}$ These conclusions were further supported by the correlation of a shorter Fe-S bond length with increased reactivity in $\mathrm{P} 450$ s and $\mathrm{CPOs},{ }^{58}$ and then later by the increase in reactivity of a selenocysteine-ligated $\mathrm{P} 450,{ }^{59}$ which exhibits even stronger electron donation to the metal center than its sulfur counterpart. It is worthy of mention that other hemedependent oxygenases, such as tryptophan 2,3-dioxygenase and indoleamine 2,3-dioxygenase, indeed utilize histidine axial ligands to direct high-valent iron intermediates, but activation of their aromatic substrates presents a distinct set of challenges requiring divergent catalytic solutions. The mechanisms of these transformations have been discussed elsewhere. ${ }^{60,61}$

The decades of P450-centered research summarized above illustrate how the interplay between peptide and cofactor can achieve reactivity that is nonexistent with either individual component. The hydroxylation pathway is just one of many examples: Nature has tuned the P450 peptide-heme interaction for many other catalytic functions. From the perspective of the protein engineer, a question that naturally follows is: can this remarkable catalytic machinery be hijacked for abiological reactions and likewise tuned to achieve useful levels of activity and selectivity?

\subsection{New Hemoprotein Activities Emerge}

In recent years, our understanding of reactions catalyzed by hemoproteins and the characterization of their reaction intermediates have been leveraged to develop new reactivities, which, combined with engineering techniques such as directed evolution, have furnished a suite of powerful hemoprotein catalysts. The examples recounted below are not intended to serve as a detailed analysis of contributions to synthetic methodology, but rather to summarize that which is currently possible with hemoprotein biocatalysts. 
Inspired by the powerful transition metal-catalyzed carbene-transfer reactions developed by synthetic chemists, ${ }^{62}$ Coelho, Brustad, and coworkers hypothesized that the heme cofactor could form analogous metal-carbenoid intermediates, as they would have an isolobal relationship with compound I. ${ }^{63}$ The carbene could then be transferred, for example, to an olefin substrate to form a cyclopropane product, similar to native P450-catalyzed epoxidation reactions. Indeed, $\mathrm{P} 450_{\mathrm{BM} 3}$ exhibited activity for the cyclopropanation of styrene with ethyl diazoacetate (EDA) as the carbene precursor, which forms the iron-carbenoid intermediate upon loss of $\mathrm{N}_{2} \cdot{ }^{64}$ Although this reaction is also catalyzed by free hemin in the presence of dithionite, the protein environment enforced a different selectivity of the product configuration. Screening a collection of P450 variants identified $\mathrm{P} 450_{\mathrm{BM}}$-CIS, which catalyzed the reaction with 199 total turnovers (TTNs), a $71: 29$ cis/trans ratio, and up to a 94\% enantiomeric excess (\% ee) - a significant improvement in both activity and selectivity over the cofactor alone.

Coelho and Brustad then initiated a directed evolution campaign to generate even more efficient catalysts, screening this new function in whole Escherichia coli cells. Their experiments suggested that the cofactor was predominantly active in the $\mathrm{Fe}(\mathrm{II})$ state, as the reaction occurred optimally in the presence of dithionite and the absence of $\mathrm{O}_{2}$. Moreover, reduction of the cofactor by the native NADPH-dependent reductase domain was unsuccessful, suggesting that the nonnative substrate fails to trigger the necessary shift in the iron's spin state, as observed in the native reaction sequence (Figure 2). These roadblocks to enzyme-catalyzed cyclopropanation in vivo were circumvented by mutating the axial cysteine ligand, which, as described above, plays a major role in tuning the electronics of the cofactor. ${ }^{65}$ Indeed, substitution with the less electron-donating serine in $\mathrm{P} 450_{\mathrm{BM} 3}$ (named $\mathrm{P} 411_{\mathrm{BM} 3}$ for the Soret band shift from $450 \mathrm{~nm}$ to $411 \mathrm{~nm}$ ) resulted in a $127 \mathrm{mV}$ increase in the resting-state reduction potential $\left(E^{\circ}\right.$, Fe[III/II $\left.]=-293 \mathrm{mV}\right)$, bringing it into 
the range of the reductase domain $\left(E^{\circ} \mathrm{NADP}^{+} / \mathrm{NADPH}=-320 \mathrm{mV}\right)$. Exchanging the axial cysteine for serine in $\mathrm{P} 450_{\mathrm{BM}_{3}-\mathrm{CIS}}$ (furnishing $\mathrm{P} 411_{\mathrm{BM} 3}-\mathrm{CIS}$ ) abolished the competing epoxidation reaction, even in the presence of $\mathrm{O}_{2}$. However, the P411 enzyme catalyzed the styrene cyclopropanation reaction with up to $67,800 \mathrm{TTN}$ in whole cells. ${ }^{65}$

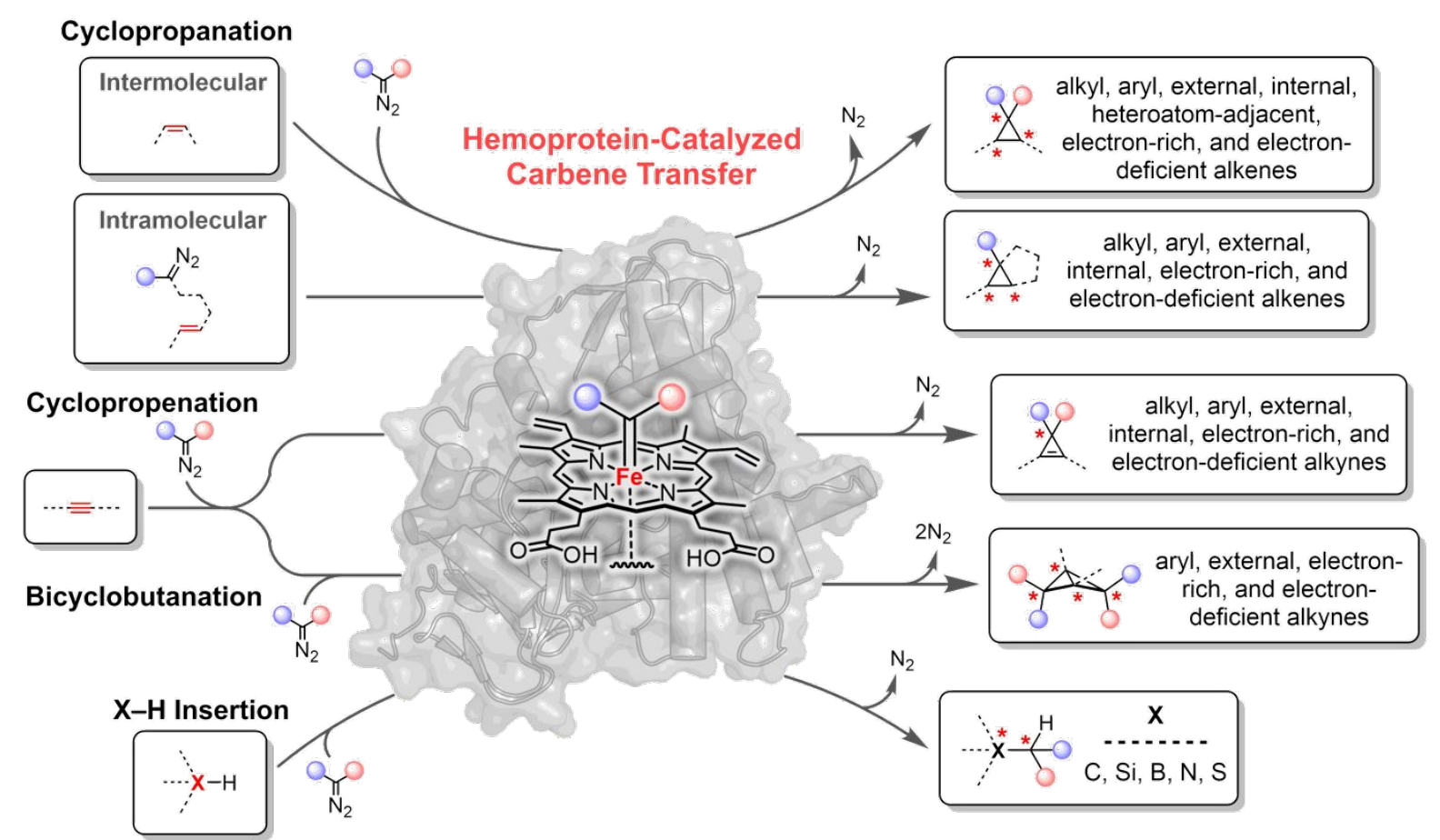

Figure 3. Summary of abiological carbene-transfer reactions catalyzed by hemoproteins. The red asterisks indicate possible chiral centers in the reaction products; the red and blue spheres indicate the possibility of variable functional groups originating from the diazo-bearing substrates.

These pioneering studies opened the floodgates to a wave of abiological reactions catalyzed by hemoproteins (Figure 3), of which many sport substitutions of key active-site residues distinguished by mechanistic research. A pool of olefin cyclopropanation catalysts has now been engineered to address several reactivity and selectivity challenges within the context of this valuable transformation. ${ }^{66-78}$ The concept of carbene transfer to $\pi$ systems has also been expanded to include alkyne substrates, from which the highly strained cyclopropene and bicyclobutane products are furnished in high yield and with excellent selectivity. ${ }^{79,80}$ Additionally, hemoproteins 
Hemoproteins have also been discovered and engineered to act as efficient transferases of nitrene intermediates, similar to carbenes. That hemoproteins could insert nitrene intermediates into $\mathrm{C}-\mathrm{H}$ bonds was shown as far back as $1985 .{ }^{91}$ It was not until 28 years later, however, that this reactivity was exploited and improved upon by directed evolution to achieve multiple turnovers (Figure 4). McIntosh, Coelho, and coworkers demonstrated that a cyclopropanating enzyme, P411 $1_{\mathrm{BM} 3}$-CIS, could catalyze an intramolecular $\mathrm{C}-\mathrm{H}$ amination reaction of the 2,4,6- 
triethylbenzene-1-sulfonyl azide nitrene precursor (wherein the loss of $\mathrm{N}_{2}$ drives formation of an iron-nitrenoid, analogous to the carbene-transfer reaction) with up to $680 \mathrm{TTN} ;{ }^{92}$ Singh and coworkers engineered P450s for a similar purpose ${ }^{93}$ An intermolecular version of this reaction was later established with tosyl azide and 4-ethylanisole. ${ }^{94}$ Aziridination of olefin substrates was also achieved with engineered P411 catalysts, using the same nitrene precursor. ${ }^{95}$ Recent advances in synthetic methodology, ${ }^{96}$ and subsequent discovery of a natural P450 nitrene transferase, BezE,${ }^{97}$ however, inspired researchers in our laboratory to turn to hydroxylamine esters as a nitrene source, which could furnish unprotected amine products in a single step. Engineered hemoproteins were active with these nitrene precursors in the asymmetric aminohydroxylation of olefin substrates, the top variants exhibiting impressive levels of activity and selectivity. ${ }^{98}$ More recently, a lineage of P411s was engineered to insert these unprotected nitrenes directly into primary, secondary, and tertiary $\mathrm{C}\left(s p^{3}\right)-\mathrm{H}$ bonds, an invaluable transformation that currently has no synthetic counterpart. ${ }^{99}$

Throughout this expansion of carbene- and nitrene-transfer reactions catalyzed by hemoproteins, the choice of hemoprotein has also grown. P450s, cytochromes $c,{ }^{84}$ myoglobins, ${ }^{70}$ protoglobins, ${ }^{66}$ and a nitric oxide dioxygenase (NOD) ${ }^{66}$ have all served as starting points for sitespecific mutagenesis or directed evolution to engineer more active and more selective biocatalysts. Furthermore, an assortment of both natural and noncanonical amino acids has been explored as axial ligands to the heme. ${ }^{100}$ Following the Hilvert Lab's discovery that an $N$-methyl-His axial ligand enhanced the native reactivity of ascorbate peroxidase and the peroxidase activity of myoglobin, ${ }^{101,102}$ Carminati and Fasan demonstrated that a myoglobin variant presenting this noncanonical amino acid to a synthetic iron-2,4-diacetyl deuteroporphyrin IX cofactor catalyzed the cyclopropanation of both electron-rich and electron-poor olefins, of which the latter had 
remained a challenging substrate for such biocatalytic transformations..$^{75}$ Interestingly, their experimental observations suggested that the reaction mechanism had been altered, and now proceeded down a stepwise radical pathway rather than the previously hypothesized concerted carbene-transfer pathway. We anticipate more such observations as the hemoprotein platform is pushed in creative new directions to overcome contemporary synthetic challenges.

The studies recounted above demonstrate how iron-carbenoid and iron-nitrenoid intermediates within an enzyme active site can be channeled toward the construction of useful bonds, but these highly reactive species can also escape down reaction pathways that generate undesirable side products. In carbene-transfer reactions, alkylation of the heme cofactor or nearby protein residues is a limiting factor in maximizing catalytic turnovers. ${ }^{103}$ While this side reaction is also possible in nitrene-transfer reactions, reduction of the nitrene to a primary amine is perhaps the most problematic side pathway, particularly in the context of intermolecular reactions. ${ }^{94,104} \mathrm{In}$ both carbene- and nitrene-transfer reactions, substrates bearing multiple modes or sites of reactivity further exacerbate this problem, as additional pathways of intermediate decay can result in diminished chemo-, regio-, and stereoselectivity. While these obstacles should always be considered when embarking on a new reaction, it is worth recognizing the benefits imparted by a mutable protein scaffold: in many of the carbene-transfer and virtually all of the nitrene-transfer reactions described to date, the free heme cofactor fails to produce measurable quantities of the desired products. And, in the cases where activity is observed, the TTNs and enantiomeric excesses pale in comparison to those with the engineered hemoproteins. In summary, the laboratory-evolved protein architecture plays a crucial role in directing reactive intermediates along the desired reaction pathways, much the same way that the natural versions of these cytochromes P450 direct compounds I and II. 


\section{NONHEME IRON}

\subsection{Reactions of Ferrous Iron with Oxygen Species}

Ferrous iron alone can also be a catalyst in reactions with various oxygen species. Although the oxidation of $\mathrm{Fe}(\mathrm{II})$ to $\mathrm{Fe}(\mathrm{III})$ in the presence of $\mathrm{O}_{2}$ in aqueous solutions generally leads to the undesired precipitation of ferric hydroxide complexes, especially in alkaline solutions, other conditions that promote useful iron-catalyzed reactions have been described. In the Fenton reaction, for instance, $\mathrm{Fe}(\mathrm{II})$ disproportionates $\mathrm{H}_{2} \mathrm{O}_{2}$ to $\mathrm{HO} \bullet$ and $\mathrm{HOO}$, and produces $\mathrm{H}_{2} \mathrm{O}$ as a byproduct. ${ }^{105}$ The resulting radical species can then oxidize organic compounds, which is the basis of the reaction's application to the purification of groundwater and soils contaminated with hydrocarbons. ${ }^{106} \mathrm{Fe}(\mathrm{II})$ in the presence of peroxy acids is converted to the $\mathrm{Fe}$ (IV)-oxo (ferryl) intermediate, which was demonstrated to catalyze $\mathrm{C}-\mathrm{H}$ oxidation reactions that later helped establish the stepwise model (HAT and oxygen rebound) for many biological oxidations. ${ }^{107,108}$ Reaction of aqueous $\mathrm{Fe}(\mathrm{II})$ with ozone $\left(\mathrm{O}_{3}\right)$ also produces the reactive ferryl species. ${ }^{109}$ Under these conditions, ketones and other byproducts were generated from one- and two-electron oxidations of cyclic alcohols. ${ }^{110}$ In the Gif oxygenation systems, these ferryl species are formed directly from $\mathrm{O}_{2}$ in the presence of reductants $(\mathrm{Zn}$ or $\mathrm{NaS})$ and pyridine. ${ }^{111-113}$ While the culmination of this body of work has indeed yielded catalytic systems that can functionalize strong $\mathrm{C}-\mathrm{H}$ bonds, many of these fundamentally important reactions suffer from unproductive oxidation and precipitation of the catalyst, a general lack of control over intermediary radical species, and limited regio- and stereoselectivity, hindering their applications more broadly.

Nonheme iron-dependent oxygenases, however, effect similar $\mathrm{C}-\mathrm{H}$ functionalization reactions efficaciously by protecting the ferrous cofactor from unproductive oxidation, tuning reactivity with $\mathrm{O}_{2}$, and positioning substrates such that reactive intermediates are guided down the desired pathway. Here, we narrow our focus to mononuclear Fe(II)-dependent oxygenases that 
A
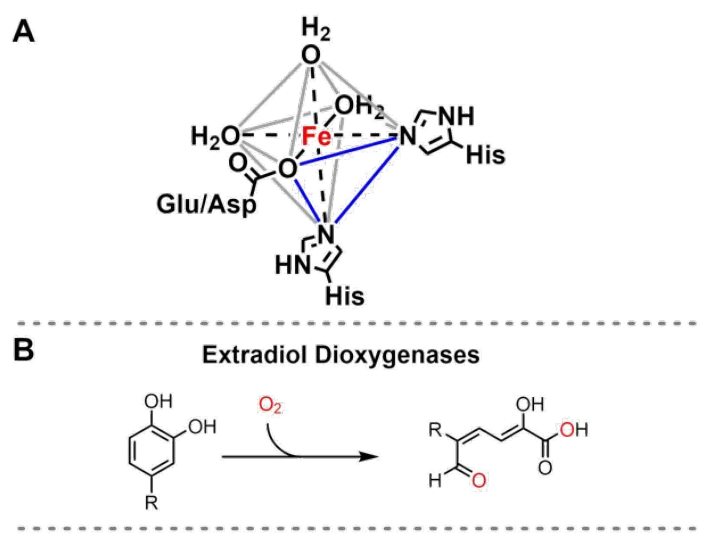$$
\text { C }
$$
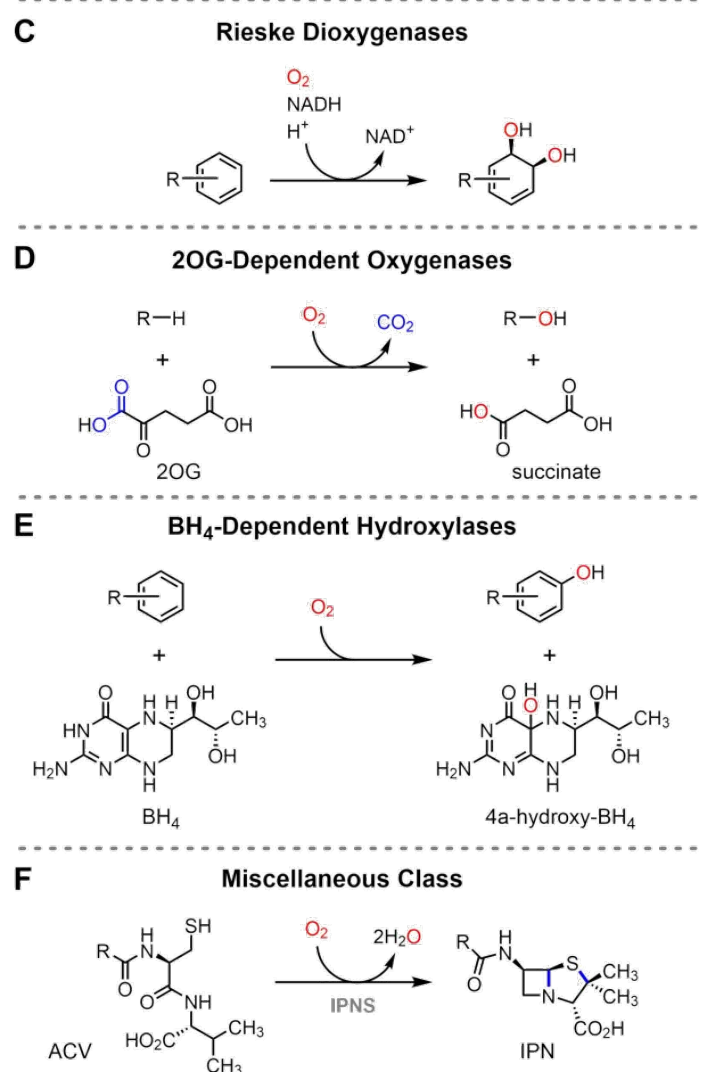

Figure 5. A, The 2-His-1-carboxylate facial triad iron-binding motif. The vertices of one face of the octahedron are occupied by the three protein ligands (blue triangle). The general reactions catalyzed by each of the 2-His-1-carboxylate enzyme families are shown in B-F. The conversion of $\delta$ - $(\mathrm{L}-$ $\alpha$-aminoadipoyl)-L-cysteinyl-D-valine

(ACV) to isopenicillin $N$ by the oxidase IPNS is a representative example in the miscellaneous class, which includes oxygenases, oxidases, and peroxidases. employ the 2-His-1-carboxylate iron-binding motif. These enzymes catalyze a remarkable diversity of oxidative transformations stemming from this ostensibly simple, earth-abundant metal, providing another example of how the protein environment can modulate cofactor reactivity and maximize its catalytic potential.

\subsection{C-H Oxidation Reactions Catalyzed by 2- His-1-Carboxylate Enzymes}

2-His-1-carboxylate enzymes activate $\mathrm{O}_{2}$ for a diversity of $\mathrm{C}-\mathrm{H}$ oxidation reactions with an ironbinding motif comprised of two histidines and one glutamate or aspartate..$^{2,114-116}$ This facial triad of protein ligands occupies the vertices of one face of the octahedral iron, leaving open three coordination sites for waters, substrates, cosubstrates, and various species of oxygen (Figure 5A). Because of the divergence in requirements for additional co-substrates and cofactors, enzymes that utilize this motif are divided into the following five families: the extradiol dioxygenases (Figure 5B), ${ }^{117}$ the Rieske dioxygenases (Figure 5C), ${ }^{118}$ the 2-oxoglutarate 


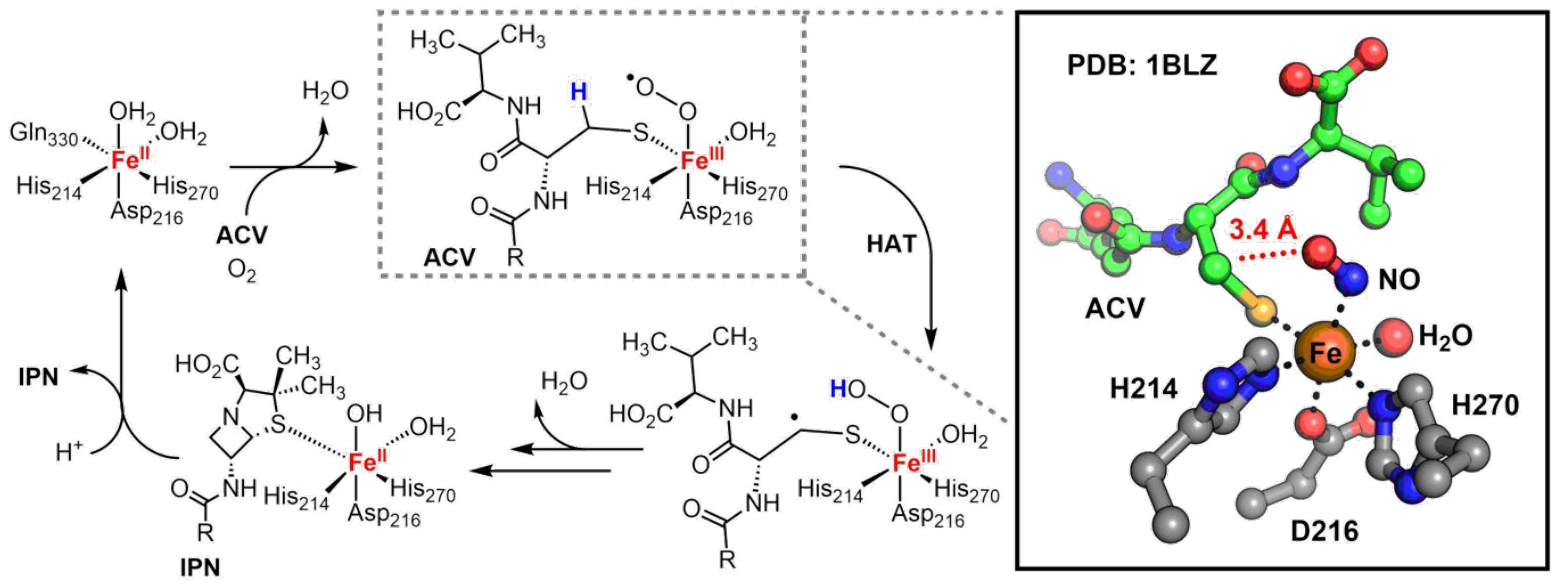

Figure 6. Abbreviated mechanism of the conversion of $L-\delta$-aminoadipoyl-L-Cys-D-Val (ACV, green) to isopenicillin $N$ (IPN) catalyzed by IPNS. The crystal structure of the NO-bound complex (right, PDB: 1BLZ), a mimic of the HAT-initiating ferric superoxide intermediate, demonstrates how the protein-enforced orientation of the iron-bound substrate results in productive reactivity.

(2OG)-dependent oxygenases (Figure 5D), ${ }^{119}$ the tetrahydrobiopterin $\left(\mathrm{BH}_{4}\right)$-dependent hydroxylases (Figure 5E), ${ }^{120}$ and a miscellaneous class that includes isopenicillin $N$-synthase (IPNS), ${ }^{121,122} \quad(S)$-2-hydroxypropyl-1-phosphonate $\quad$ epoxidase $\quad(H p p E),{ }^{123} \quad 2-$ hydroxyethylphosphonate dioxygenase (HEPD), ${ }^{124}$ methylphosphonate synthase (MPnS) (Figure 5F), ${ }^{125}$ and 1-aminocyclopropane-1-carboxylate oxidase (ACCO). ${ }^{126}$ The references logged above provide a more comprehensive discussion of each individual family, as the staggeringly large catalogue of chemical transformations described by these enzymes is outside the scope of this Perspective. Biomimetic nonheme iron model complexes have also been reviewed extensively. ${ }^{127-}$ 129

Despite the catalytic diversity of 2-His-1-carboxylate enzymes, a general strategy to regulate entry into the reaction cycle has emerged. The ferrous resting state of the cofactor renders it, in principle, highly susceptible to unproductive oxidation, necessitating a mechanism to protect the active site during periods of inactivity. Similar to P450s (vide supra), the binding of substrates 

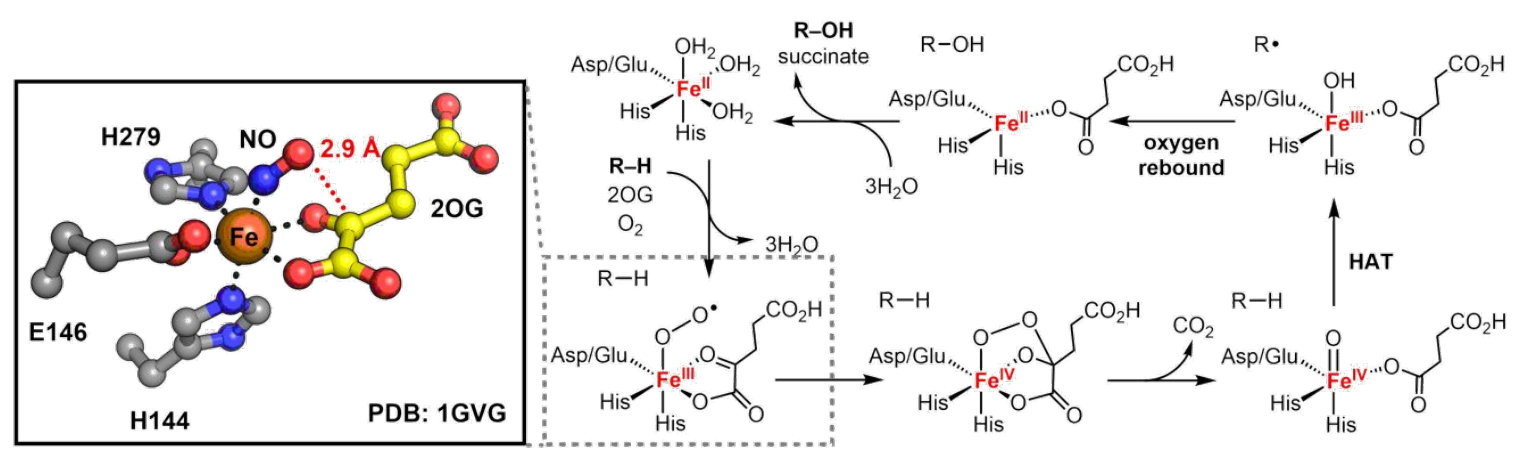

Figure 7. Established mechanism of aliphatic $\mathrm{C}-\mathrm{H}$ hydroxylation catalyzed by $2 \mathrm{OG}$-dependent oxygenases. The NO-bound crystal structure of CAS1 (left, PDB: 1GVG) shows a close proximity of the distal oxygen of the ferric superoxide intermediate to $\mathrm{C} 2$ of $2 \mathrm{OG}$ (yellow), leading to oxidative cleavage of the co-substrate to succinate and $\mathrm{CO}_{2}$, and ultimately hydroxylation of the primary substrate.

triggers the dissociation of one or more coordinated water molecules, constituting a proteincontrolled shift in the ligand sphere to promote a five-coordinate Fe(II) center, which opens a site for binding of $\mathrm{O}_{2} \cdot{ }^{2,115}$ The displacement of water with anionic ligands is also thought to decrease the Fe(III/II) reduction potential for productive oxidation of the cofactor. ${ }^{115}$ Whereas the substrates or co-substrates of the extradiol dioxygenases, 2OG-dependent oxygenases, and IPNS fill this role by directly coordinating to the iron, ${ }^{117,119,130}$ the $\mathrm{BH}_{4}$-dependent hydroxylases and Rieske dioxygenases, whose substrates contribute no additional anionic ligands, effect a similar outcome by bidentate coordination of the protein's carboxylate ligand. ${ }^{118,120}$

The steps following substrate binding and $\mathrm{O}_{2}$ activation in each of the 2-His-1-carboxylate families diverge, giving rise to an assortment of structurally and electronically distinct intermediates. Nevertheless, a unifying theme concerning the protein's influence over the reaction progression is clear: the polypeptide scaffold binds the substrate, co-substrate, or additional cofactor involved in the subsequent step in an orientation that encourages productive interaction with the intermediary iron-bound oxygen species. In IPNS, the end-on ferric superoxide initiates a HAT from the substrate $\mathrm{C}-\mathrm{H}$ bond neighboring the iron-coordinated thiolate, the committed step 


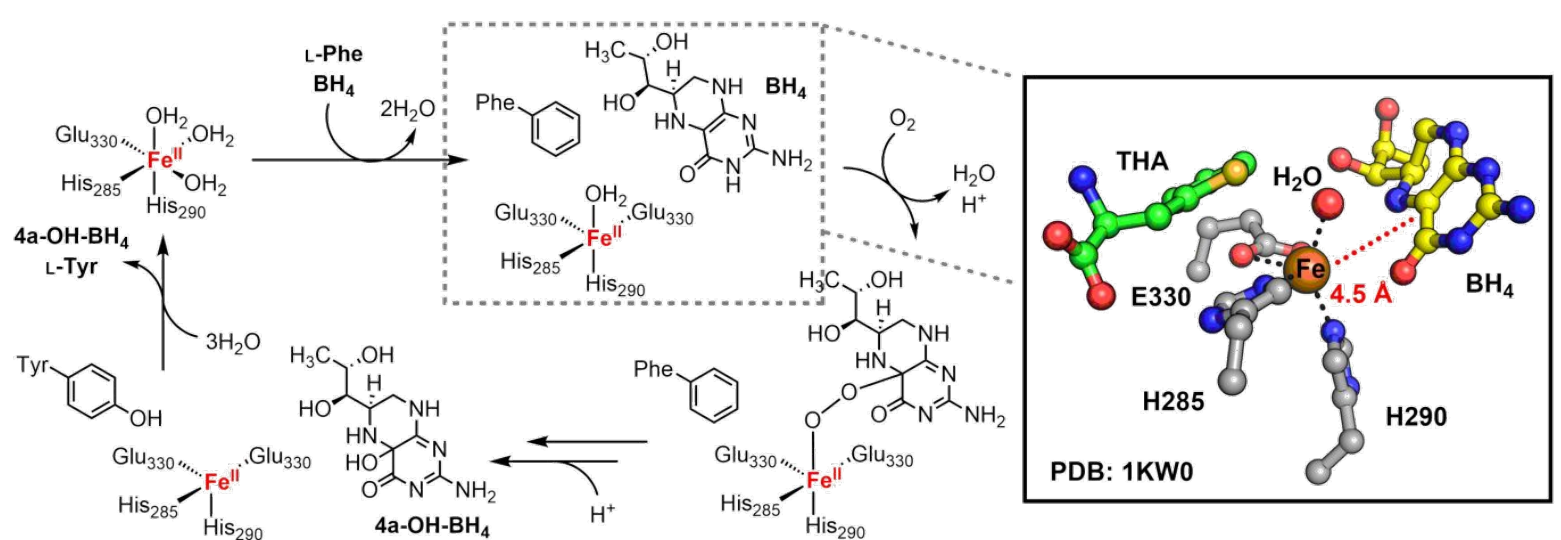

Figure 8. Abbreviated mechanism of the conversion of L-phenylalanine to L-tyrosine catalyzed by phenylalanine hydroxylase. The $\mathrm{BH}_{4}$-bound crystal structure with the 3-(2-thienyl)-L-alanine (THA, green) substrate analogue (right, PDB: 1KW0) shows how the protein orients the two cofactors in such a way to achieve reductive cleavage of $\mathrm{O}_{2}$ and oxidation of the aromatic substrate.

leading to $\mathrm{C}-\mathrm{N}$ and $\mathrm{C}-\mathrm{S}$ bond formation. ${ }^{122}$ The juxtaposition of the implicated atoms was shown clearly in the NO-bound crystal structure (PDB: 1BLZ), wherein the distal oxygen of the $\mathrm{O}_{2}$ surrogate is in close proximity to the target carbon (Figure 6). ${ }^{130}$ Similar observations were made in the NO-bound crystal structures of the 2OG-dependent enzymes clavaminate synthase 1 (CAS1, PDB: 1 GVG) and WelO5 (PDB: 5IQV). ${ }^{131,132}$ In these cases, however, the distal oxygen of the $\mathrm{O}_{2}$ surrogate is poised to attack $\mathrm{C} 2$ of the co-substrate $2 \mathrm{OG}$, which ultimately provokes $\mathrm{O}-\mathrm{O}$ bond
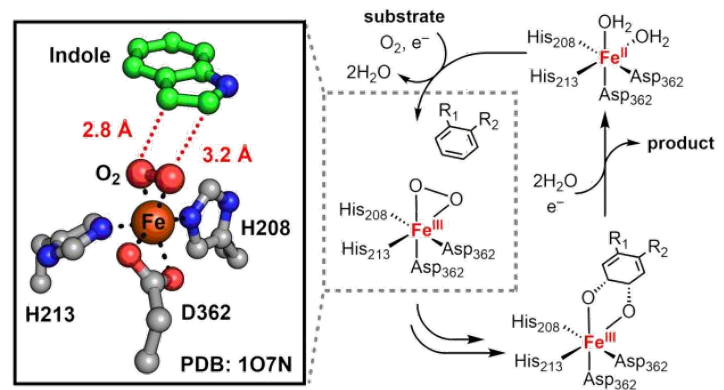

Figure 9. A side-on binding orientation of $\mathrm{O}_{2}$ to the iron cofactor in the Rieske dioxygenase family, as observed in the crystal structure of NDO (left, PDB: 1O7N) with the indole substrate analogue (green), results in synhydroxylation of aromatic substrates. scission and ferryl formation (Figure 7). In the

$\mathrm{BH}_{4}$-dependent hydroxylases, a bridged Fe(II)$\mathrm{O}-\mathrm{O}-\mathrm{BH}_{4}$ intermediate is thought to precede ferryl formation and substrate oxidation, again necessitating a propinquity of the two cofactors. ${ }^{133,134}$ Indeed, this was observed in a crystal structure of the phenylalanine hydroxylase ternary complex with the 3-(2- 
thienyl)-L-alanine (THA) substrate analogue (PDB: 1KW0, Figure 8). ${ }^{135}$ The Rieske and extradiol dioxygenases leverage a side-on binding mode of $\mathrm{O}_{2}$ to affect product formation. In the former family, the orientation of the substrate results in syn-hydroxylation of the aromatic system, as was revealed by the crystal structures of naphthalene dioxygenase (NDO, PDB: 1O7N) and carbazole 1,9a-dioxygenase (CARDO, PDB: 3VMI) bearing the intermediate state (Figure 9). ${ }^{136,137}$ In the latter family, a single crystal structure depicting multiple states of the homoprotocatechuate 2,3dioxygenase (2,3-HPCD, PDB: 2IGA) reaction cycle demonstrates how the cofactor-substrate relationship promotes substrate-driven reduction of $\mathrm{O}_{2}$ and eventually cleavage of the aromatic ring (Figure 10). ${ }^{138}$ In a more recent study on 3-hydroxyanthranilate-3,4-dioxygenase (HAO), a close relative of the extradiol dioxygenases, an astonishing seven states of the reaction cycle were captured by x-ray crystallography. ${ }^{139}$ Although this enzyme does not appear to bind $\mathrm{O}_{2}$ in the same side-on orientation, the protein scaffold still guides the reaction through a similar course of events.

Several of the 2-His-1-carboxylate families form high-valent ferryl intermediates for the cleavage of strong $\mathrm{C}-\mathrm{H}$ bonds. ${ }^{140}$ Unlike those formed free in solution, these enzymatic

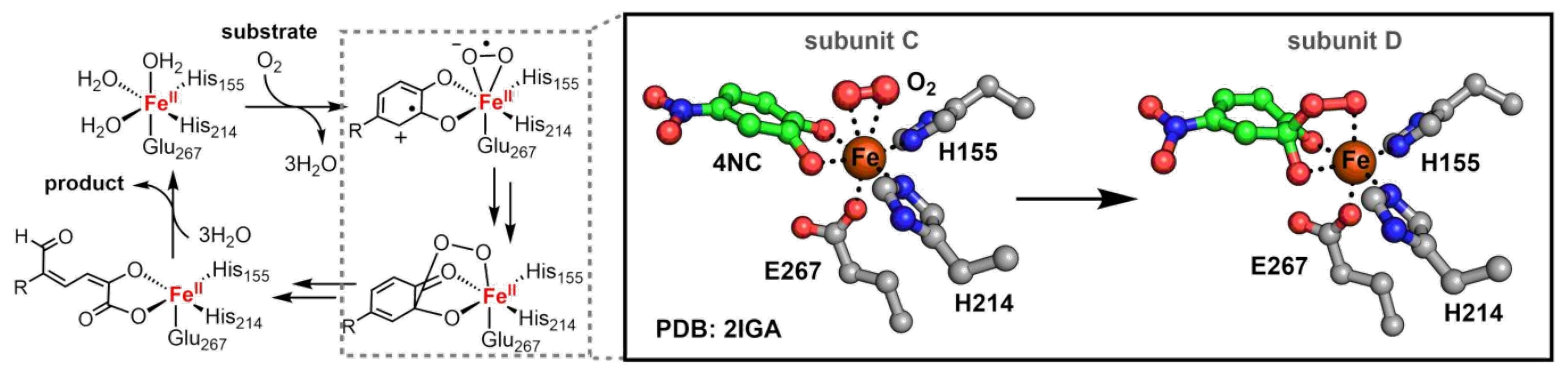

Figure 10. Abbreviated mechanism of the cleavage of catechol substrates catalyzed by members of the extradiol ring-cleaving dioxygenase family. The side-on binding mode of $\mathrm{O}_{2}$ observed in the crystal structure of 2,3-HPCD (right, PDB: 2IGA) positions the intermediate close to the correct carbon of the 4-nitrocatechol substrate (4NC, green), which results in substrate-driven reduction of $\mathrm{O}_{2}$ and ultimately insertion of both oxygens into product structure. Remarkably, multiple states of this reaction cycle were captured in different subunits of the asymmetric unit in the same crystal sample. 
intermediates are channeled with precise stereoelectronic control. 2OG-dependent oxygenases, in particular, are a testament to such precise channeling, as ferryl-mediated $\mathrm{C}-\mathrm{H}$ activation leads to an astounding diversity of transformations that, in most instances, are catalyzed with exceptional selectivity. ${ }^{141}$ In this family, the reduction of $\mathrm{O}_{2}$ and oxidative conversion of $2 \mathrm{OG}$ to succinate and $\mathrm{CO}_{2}$ results in ferryl formation, ${ }^{142-152}$ which then effects $\mathrm{C}-\mathrm{H}$ bond cleavage to yield ferrichydroxide and substrate-centered radical intermediates, a key branchpoint in 2OG-dependent oxygenase catalysis. The origin of chemoselectivity stemming from this state has been studied extensively by dissecting and comparing the mechanisms employed by the hydroxylase and halogenase subfamilies. In the hydroxylation pathway, oxygen rebound furnishes the product and regenerates the $\mathrm{Fe}(\mathrm{II})$ cofactor for subsequent turnovers (Figure 7), similar to P450-cataylzed hydroxylation reactions. ${ }^{18,119}$ In the halogenation pathway, a cis-coordinated halogen is transferred $(\mathrm{Cl} \bullet$ or $\mathrm{Br} \bullet)$ in lieu of the hydroxyl group (Figure 11). This transfer is first enabled by substitution of the iron-binding carboxylate ligand of the facial triad for an alanine or glycine, as demonstrated by the substrate-free crystal structure of the carrier-protein-dependent chlorinase SyrB2 (PDB:
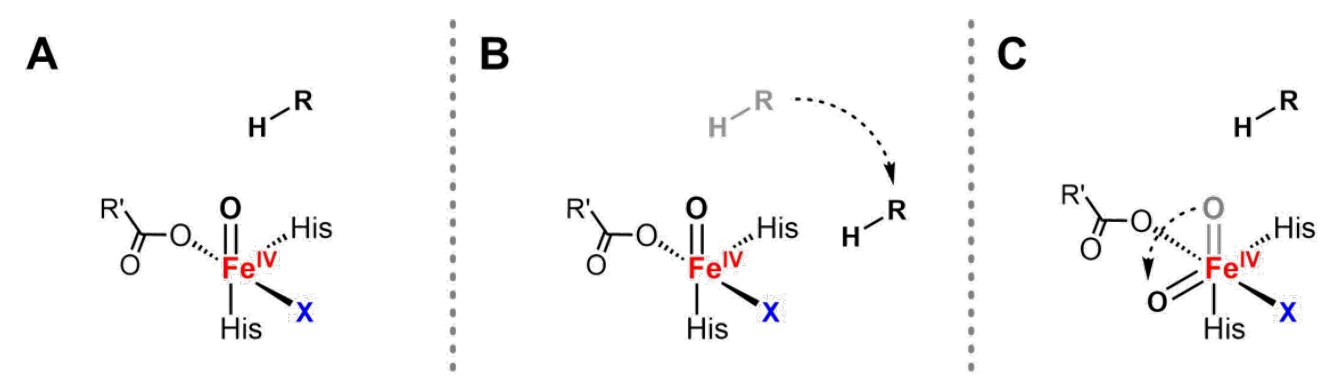

Figure 11. Comparative models showing the generalized protein-dictated orientations of the substrate and ferryl intermediate in 2OG-dependent enzyme catalysis. The inline ferryl with substrate bound directly above the oxo is the typical configuration for hydroxylation (A). Halogenation is achieved by binding the substrate such that rebound of the halogen radical is favored (B), or by reorientation of the ferryl to disfavor oxygen rebound (C). The blue $\mathbf{X}$ represents an iron-coordinated aspartate, glutamate, or halide; the substrate is depicted as $\mathrm{R}-\mathrm{H}$; the gray $\mathrm{R}-\mathrm{H}$ and iron-oxo bond are shown to illustrate the change in position of the respective species, not to be interpreted as being present in the complex. 


\subsection{The Facial Triad Supports Abiological Activity}

The astonishing catalytic repertoire of nonheme iron-dependent oxygenases, oxidases, and peroxidases bearing the 2-His-1-carboxylate facial triad has inspired researchers to investigate whether this enzymatic platform could be extended to useful abiological transformations. While this vision has indeed proven to be possible, the collection of engineered catalysts is still in its infancy. However, the future is nonetheless bright for this family of enzymes, and we anticipate that the progress summarized below is just the beginning.

Members of the 2OG-dependent halogenase subfamily hold great biocatalytic potential within the confines of their native catalytic function, as there is currently a paucity of methods to directly halogenate aliphatic $\mathrm{C}-\mathrm{H}$ bonds with a high degree of selectivity. ${ }^{162-166}$ Our understanding of these enzymes also led some researchers to investigate whether other anionic species that would likely coordinate to the cofactor could be coupled to intermediate substrate radicals via an analogous mechanism. Indeed, trace levels of nitration and azidation activity were detected in SyrB2 preparations with the native substrate and substrate analogues, constituting an important 
abiological addition to the growing number of enzymatic $\mathrm{C}-\mathrm{H}$ functionalization reactions (Figure 12A). ${ }^{167}$ In recent years, a few other halogenases that operate on freestanding amino acids and other small molecules have also been shown to catalyze the azidation reaction. ${ }^{168,169}$ Although direct azidation of amino acids may prove to be a useful tool for bioorthogonal chemistry applications, ${ }^{170}$ these enzymes have yet to be engineered for this specific purpose. During future directed evolution campaigns, the second-sphere residues analogous to those implicated in ferryl redirection by the studies of native and engineered halogenases, ${ }^{132,171}$ as depicted in Figure 11C, are sensible targets for site-saturation mutagenesis and screening to enhance these activities.

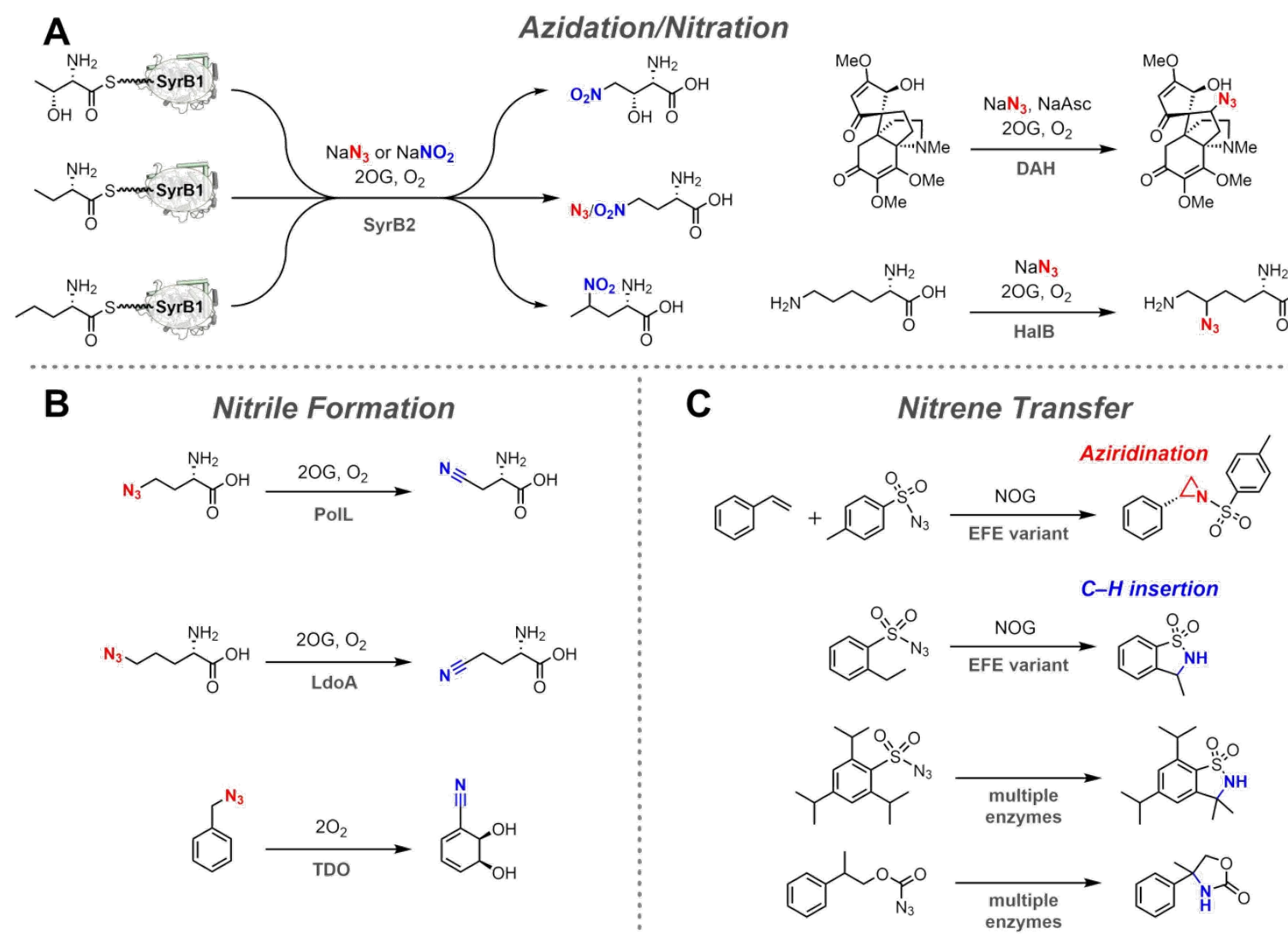

Figure 12. Abiological azidation and nitration (A), nitrile formation (B), and nitrene-transfer (C) reactions catalyzed by 2-His-1-carboxylate enzymes. S-SyrB1 represents the carrier-protein appended to the substrate by phosphopantetheine; $\mathrm{NOG}=\mathrm{N}$-oxalylglycine, a structural mimic of 2OG. 
Azide-bearing amino acids have also been explored as substrates for 2OG-dependent oxygenases. In a recent study, the native hydroxylases PolL and LdoA catalyzed the oxidative conversion of these azidated substrates to nitrile products (Figure 12B). ${ }^{172}$ Further investigation demonstrated the requirement of both $\mathrm{O}_{2}$ and 2OG, suggesting that the reaction still proceeds by ferryl formation and HAT, and that the azido moiety acts as an assisting group. A similar finding was also reported in the Rieske dioxygenase family, wherein toluene dioxygenase (TDO) converted a benzyl azide to a benzyl nitrile. ${ }^{173}$ In both cases, iron-nitrenoid intermediates were proposed as a possible branchpoint after substrate hydroxylation.

Goldberg, Knight, and coworkers recently demonstrated that similar iron-nitrenoid intermediates could effect nitrene-transfer reactions (Figure 12C) analogous to those catalyzed by engineered hemoproteins (vide supra). ${ }^{174}$ Activity for the intermolecular aziridination of styrene and the intramolecular benzylic $\mathrm{C}-\mathrm{H}$ insertion of 2-ethylbenzenesulfonyl azide was detected with the 2OG-dependent ethylene-forming enzyme (EFE). EFE variants exhibiting improvements in both activity and stereoselectivity were obtained by directed evolution, establishing that this family of enzymes can also be tuned for abiological catalysis. A subsequent study by Vila, Steck, and coworkers suggests that nitrene transferase activity may be a common side reactivity of 2-His-1carboxylate enzymes, as various 2OG-dependent oxygenases and Rieske dioxygenases were also shown to facilitate similar nitrene-transfer reactions. ${ }^{175}$

The presence of multiple iron coordination sites left unoccupied by protein ligands creates attractive opportunities for engineering this enzymatic platform using exogenous ligands to tune the reactivity of the cofactor (Figure 5A). Indeed, Goldberg and Knight discovered the native cosubstrate, 2OG, of EFE enhanced the activity of the aziridination and $\mathrm{C}-\mathrm{H}$ insertion reactions with both the native and engineered versions of the enzyme. ${ }^{174}$ Other anionic ligands, such as acetate 
and $N$-oxalylglycine (NOG), further boosted the activity of both reactions and improved the chemoselectivity of the $\mathrm{C}-\mathrm{H}$ insertion reaction. Although they did not determine the mechanisms of these enhancements, their observations demonstrate that exogenous ligands are a further handle for tuning novel reactivities. This expanded access to the iron provides an additional, flexible component upon which the protein scaffold can draw to guide reactive intermediates down new pathways.

\section{ENGINEERING THE FUTURE}

\subsection{From Comprehension to Application}

The machinery of natural enzymes has fueled the imagination of researchers for decades. But is an understanding of mechanism a prerequisite to engineering an abiological function? Luckily, the answer is no. While the disparities between our understanding of the chemistry occurring at the enzyme active site and the astounding complexity of interactions that contribute to protein folding, dynamics, and catalysis preclude us from designing most new biocatalysts de novo (at least for the time being), we can engineer new enzymes from existing scaffolds even if the intricacies of such scaffolds cannot be fully deconstructed. Nevertheless, knowledge gained from mechanistic studies, while not strictly required, can certainly assist in discovering new reactivities and streamlining engineering processes such that desired catalytic enhancements can be achieved on reasonable timescales. To bridge the gap between comprehension and application, we introduce the challenges of engineering natural enzymes for abiological chemistry, and then provide examples of how mechanistic knowledge of both natural and laboratory-evolved enzymes has guided protein engineers in tuning iron-dependent oxygenases.

From controlling the flow of electrons and protons to protecting the active-site architecture from oxidative inactivation, natural evolution has honed iron-dependent oxygenases into 
sophisticated molecular machines. The driving force behind this process is the selective advantage conferred by the products, which promote the survival of an organism bearing mutations that enhance the reaction outcome. Over time, this selective pressure can furnish a highly refined enzyme. In the context of evolving a biocatalyst for an abiological reaction, the protein engineer must first discover an enzyme exhibiting measurable activity for the desired reaction, generate mutants of this parent enzyme, and then foster the desired outcome by compounding beneficial mutations and rejecting mutations that fail to yield improvements. ${ }^{176}$ In principle, this process could produce enzymes comparable to the products of natural evolution. In practice, however, time constitutes a major limitation: screening the entire landscape of possible mutations in the context of even the smallest of proteins is impracticable. Moreover, many abiological reactions cannot be coupled to the fitness of an organism, or the products fail to produce a distinctive fluorogenic handle that would allow for rapid detection. Most efforts necessitate use of more time-intensive analytical techniques that decrease capacity to screen sequences (e.g., liquid and gas chromatography). Consequently, we resort to strategies to create smarter, experimentally tractable libraries that allow us to climb local fitness peaks (e.g., site-saturation mutagenesis). ${ }^{177}$ Although such a process will likely miss out on some of the characteristics that make natural enzymes so powerful, the results are nonetheless impressive.

An understanding of natural enzyme mechanism, even one that is rudimentary, can point the engineer to specific residues or regions of a protein structure that are important to catalysis. ${ }^{178}$ This knowledge can then be applied to the design of libraries for engineering. In the context of iron-dependent oxygenases, this is clearly exemplified in the transformation of $\mathrm{P} 450_{\mathrm{BM} 3}$ to $\mathrm{P}_{411_{\mathrm{BM} 3}}$ (vide supra): although the entirety of the contemporary $\mathrm{P} 450 \mathrm{C}-\mathrm{H}$ activation model was likely superfluous, knowledge of the axial ligand's electronic effects on the heme cofactor was 
pivotal to the discovery of $\mathrm{P} 450_{\mathrm{BM} 3}$ variants that exhibited redox potentials suited for cyclopropanation in whole cells. ${ }^{65}$ Likewise, crystal structures of the $\mathrm{P} 450_{\mathrm{BM} 3}$ heme domain and engineered variants thereof have aided numerous other directed evolution campaigns in the exploration of the platform's ability to catalyze abiological reactions. ${ }^{65,94,179}$

Mechanistic investigations of laboratory-evolved variants can also confer useful information for the design of smarter libraries. A recent study of Rhodothermus marinus cytochrome $c$ engineered for $\mathrm{C}-\mathrm{Si}$ and $\mathrm{C}-\mathrm{B}$ bond formation yielded a crystal structure with an iron porphyrin-bound carbene intermediate. ${ }^{180}$ The structure revealed how mutations to a surface loop region rendered it more flexible than that of the native enzyme, an observation that was leveraged to engineer a $\mathrm{C}-\mathrm{B}$ bond-forming enzyme capable of accepting diverse trifluorodiazo alkane carbene precursors to furnish the corresponding $\alpha$-trifluoromethylated organoborane products. ${ }^{87}$ Site-saturation libraries focused on this region yielded multiple beneficial mutations, and the final variant maintained levels of activity and selectivity with a trifluorodiazo alkane substrate scope comparable to the model reaction. Computational analysis of the engineered enzyme supported the original mechanism-driven hypothesis: the heme-binding pocket positioned the iron-carbenoid intermediate such that the pro- $R$ face was exposed to the putative borane-binding pocket, while the variable alkyl substituent was arranged to have a minimal effect on the reaction outcome. ${ }^{87}$

Although the finer details of our mechanistic knowledge oftentimes lack a direct application to the engineering process, it is difficult to imagine a world where we climb to the same peaks of ingenuity without the contributions from mechanistic enzymology. It is even conceivable that some of these recent innovations, and those still to be described, already exist in the biological world, which will render their eventual discoveries all the more enchanting.

\subsection{Iron-Dependent Oxygenases in Organic Synthesis}


We are optimistic that applications of iron-dependent biocatalysts as real-world synthetic tools will grow, as the expansion of methods to selectively functionalize $\mathrm{C}-\mathrm{H}$ bonds will certainly have an impact on both the de novo synthesis and late-stage modification of drug compounds and potentially therapeutic natural products. The native oxidative functions of P450s have already been applied to such goals, whether in the hydroxylation of steroids and other useful organic molecules, ${ }^{181,182}$ or more recently in the chemoenzymatic syntheses of nigelladine A and several meroterpenoid natural products. ${ }^{183,184}$ Likewise, native 2 OG-dependent hydroxylases and halogenases have been utilized by the Renata Lab and others in the synthesis and tailoring of natural product compounds. ${ }^{185-195}$ A few examples of the abiological transformations enabled by these platforms have already surfaced: the cyclopropyl core structures of the approved drugs levomilnacipran, ticagrelor, tranylcypromine, and tasimelteon, as well as a TRPV1 antagonist drug candidate, have been constructed with engineered P450s and globins. ${ }^{196-198}$

Enzyme engineers ultimately aspire to see the products of their creativity and labor used directly in the manufacture of valuable compounds. Industrial-scale processes, however, require much more than exciting new reactivity. Space-time yield $\left(\mathrm{g} \mathrm{L}^{-1} \mathrm{~h}^{-1}\right)$ of the desired product is a key metric of overall performance, to which the activity, specificity, and stability of the enzyme are all contributing factors. From a protein engineering standpoint, advances in both experimental technologies and computational methods - to effectively increase screening capacity and narrow library sizes, respectively—will better equip us to navigate complex fitness landscapes and reach these requisite fitness peaks. However, other factors in the process must also be considered, including substrate and product titers, solvent compatibility with upstream and downstream steps, and isolation of the products in pure form. The challenges associated with incorporating 
biocatalysts into industrial processes and realistic approaches moving forward have been the subjects of several recent and comprehensive reviews. ${ }^{199-202}$

\section{CONCLUDING REMARKS}

Until the day when computational methods and de novo protein design can furnish biocatalysts capable of fulfilling our demands, leveraging our understanding of natural enzymes toward discovery and evolution of new functions remains a fruitful approach to the development of useful synthetic tools. Nature's catalytic machinery has energized the scientific community for centuries, and engineered versions of enzymes have now expanded the pool from which to draw inspiration. As in all disciplines of science, collaboration is crucial. The convergence of enzymology, synthetic chemistry, computation, and engineering is the motor that drives forward the field of biocatalysis.

\section{AUTHOR INFORMATION}

\section{Corresponding Author}

Frances H. Arnold - Division of Chemistry and Chemical Engineering, California Institute of Technology, Pasadena, California 91125, United States; orcid.org/0000-0002-4027-364X; *Email: frances@cheme.caltech.edu

\section{Authors}

Noah P. Dunham - Division of Chemistry and Chemical Engineering, California Institute of Technology, Pasadena, California 91125, United States; orcid.org/0000-0001-8006-9566

\section{Notes}

The authors declare no competing financial interest.

\section{ACKNOWLEDGEMENTS}

This work was supported by the US Army Research Office Institute for Collaborative Biotechnologies contract W911NF-19-D-0001 and the Joseph J. Jacobs Institute for Molecular Engineering for Medicine. N.P.D. was supported by the Ruth L. Kirschstein NIH Postdoctoral Fellowship (F32GM131620). We thank Professor Haoming Zhang for providing the open- and closed-state coordinates resulting from the full-length $\mathrm{P}_{450_{\mathrm{BM} 3}}$ cryo-EM structures. We also thank 
Dr. S. V. Athavale, Dr. D. C. Miller, and Dr. Z. Liu for providing helpful comments on the manuscript.

\section{REFERENCES}

(1) Silverman, R. B. Enzymes as Catalysts. In Organic Chemistry of EnzymeCatalyzed Reactions (Second Edition); Academic Press: San Diego, 2002, p 1-38.

(2) Solomon, E. I.; Brunold, T. C.; Davis, M. I.; Kemsley, J. N.; Lee, S. K.; Lehnert, N.; Neese, F.; Skulan, A. J.; Yang, Y. S.; Zhou, J. Geometric and Electronic Structure/Function Correlations in Non-Heme Iron Enzymes. Chem. Rev. 2000, 100, 235-349.

(3) Decker, A.; Solomon, E. I. Dioxygen Activation by Copper, Heme and Non-Heme Iron Enzymes: Comparison of Electronic Structures and Reactivities. Curr. Opin. Chem. Biol. 2005, 9, 152-163.

(4) Pau, M. Y. M.; Lipscomb, J. D.; Solomon, E. I. Substrate Activation for $\mathrm{O}_{2}$ Reactions by Oxidized Metal Centers in Biology. Proc. Natl. Acad. Sci. U.S.A. 2007, 104, 1835518362.

(5) Groves, J. T. The Bioinorganic Chemistry of Iron in Oxygenases and Supramolecular Assemblies. Proc. Natl. Acad. Sci. U.S.A. 2003, 100, 3569-3574.

(6) Drauz, K.; Gröger, H.; May, O. Introduction - Principles and Historical Landmarks of Enzyme Catalysis in Organic Synthesis. In Enzyme Catalysis in Organic Synthesis (Third Edition); Wiley-VCH: Weinheim, Germany, 2012, p 1-42.

(7) Chen, K.; Arnold, F. H. Engineering New Catalytic Activities in Enzymes. Nat. Catal. 2020, 3, 203-213.

(8) Munro, A. W.; Girvan, H. M.; McLean, K. J.; Cheesman, M. R.; Leys, D. Heme and Hemoproteins. In Tetrapyrroles: Birth, Life and Death; Springer New York: New York, NY, 2009, p 160-183.

(9) Lash, T. D. Origin of Aromatic Character in Porphyrinoid Systems. J. Porphyr. Phthalocyanines 2011, 15, 1093-1115.

(10) Dolphin, D.; Forman, A.; Borg, D. C.; Fajer, J.; Felton, R. H. Compounds I of Catalase and Horse Radish Peroxidase: $\pi$-Cation Radicals. Proc. Natl. Acad. Sci. U.S.A. 1971, 68, 614-618.

(11) Dawson, J. Probing Structure-Function Relations in Heme-Containing Oxygenases and Peroxidases. Science 1988, 240, 433-439.

(12) Hardison, R. C. A Brief History of Hemoglobins: Plant, Animal, Protist, and Bacteria. Proc. Natl. Acad. Sci. U.S.A. 1996, 93, 5675-5679.

(13) Ordway, G. A.; Garry, D. J. Myoglobin: An Essential Hemoprotein in Striated Muscle. J. Exp. Biol. 2004, 207, 3441-3446.

(14) Liu, J.; Chakraborty, S.; Hosseinzadeh, P.; Yu, Y.; Tian, S.; Petrik, I.; Bhagi, A.; Lu, Y. Metalloproteins Containing Cytochrome, Iron-Sulfur, or Copper Redox Centers. Chem. Rev. 2014, 114, 4366-4469.

(15) Chelikani, P.; Fita, I.; Loewen, P. C. Diversity of Structures and Properties Among Catalases. Cell. Mol. Life Sci. 2004, 61, 192-208.

(16) Welinder, K. G. Superfamily of Plant, Fungal and Bacterial Peroxidases. Curr. Opin. Struct. Biol. 1992, 2, 388-393. 
(17) Alderton, W. K.; Cooper, C. E.; Knowles, R. G. Nitric Oxide Synthases: Structure, Function and Inhibition. Biochem. J. 2001, 357, 593-615.

(18) Meunier, B.; de Visser, S. P.; Shaik, S. Mechanism of Oxidation Reactions Catalyzed by Cytochrome P450 Enzymes. Chem. Rev. 2004, 104, 3947-3980.

(19) Huang, X.; Groves, J. T. Oxygen Activation and Radical Transformations in Heme Proteins and Metalloporphyrins. Chem. Rev. 2018, 118, 2491-2553.

(20) Sono, M.; Roach, M. P.; Coulter, E. D.; Dawson, J. H. Heme-Containing Oxygenases. Chem. Rev. 1996, 96, 2841-2888.

(21) Poulos, T. L. Heme Enzyme Structure and Function. Chem. Rev. 2014, 114, 39193962.

(22) Baglia, R. A.; Zaragoza, J. P. T.; Goldberg, D. P. Biomimetic Reactivity of OxygenDerived Manganese and Iron Porphyrinoid Complexes. Chem. Rev. 2017, 117, 13320-13352.

(23) Momenteau, M.; Reed, C. A. Synthetic Heme-Dioxygen Complexes. Chem. Rev. 1994, 94, 659-698.

(24) Costas, M. Selective C-H oxidation catalyzed by metalloporphyrins. Coord. Chem. Rev. 2011, 255, 2912-2932.

(25) Sahu, S.; Goldberg, D. P. Activation of Dioxygen by Iron and Manganese Complexes: A Heme and Nonheme Perspective. J. Am. Chem. Soc. 2016, 138, 11410-11428.

(26) Fujii, H. Electronic Structure and Reactivity of High-Valent Oxo Iron Porphyrins. Coord. Chem. Rev. 2002, 226, 51-60.

(27) Schlichting, I.; Berendzen, J.; Chu, K.; Stock, A. M.; Maves, S. A.; Benson, D. E.; Sweet, R. M.; Ringe, D.; Petsko, G. A.; Sligar, S. G. The Catalytic Pathway of Cytochrome P450cam at Atomic Resolution. Science 2000, 287, 1615-1622.

(28) de Visser, S. P.; Shaik, S. A Proton-Shuttle Mechanism Mediated by the Porphyrin in Benzene Hydroxylation by Cytochrome P450 Enzymes. J. Am. Chem. Soc. 2003, 125, 74137424.

(29) Newcomb, M.; Toy, P. H. Hypersensitive Radical Probes and the Mechanisms of Cytochrome P450-Catalyzed Hydroxylation Reactions. Acc. Chem. Res. 2000, 33, 449-455.

(30) Seto, Y.; Guengerich, F. P. Partitioning Between $N$-Dealkylation and $N$ Oxygenation in the Oxidation of $N, N$-Dialkylarylamines Catalyzed by Cytochrome P450 2B1. $J$. Biol. Chem. 1993, 268, 9986-9997.

(31) Goto, Y.; Matsui, T.; Ozaki, S.-i.; Watanabe, Y.; Fukuzumi, S. Mechanisms of Sulfoxidation Catalyzed by High-Valent Intermediates of Heme Enzymes: Electron-Transfer vs Oxygen-Transfer Mechanism. J. Am. Chem. Soc. 1999, 121, 9497-9502.

(32) Anzai, Y.; Li, S.; Chaulagain, M. R.; Kinoshita, K.; Kato, F.; Montgomery, J.; Sherman, D. H. Functional Analysis of MycCI and MycG, Cytochrome P450 Enzymes Involved in Biosynthesis of Mycinamicin Macrolide Antibiotics. Chem. Biol. 2008, 15, 950-959.

(33) Rettie, A.; Rettenmeier, A.; Howald, W.; Baillie, T. Cytochrome P-450 — Catalyzed Formation of $\Delta^{4}$-VPA, a Toxic Metabolite of Valproic Acid. Science 1987, 235, 890-893.

(34) Kramlinger, V. M.; Nagy, L. D.; Fujiwara, R.; Johnson, K. M.; Phan, T. T. N.; Xiao, Y.; Enright, J. M.; Toomey, M. B.; Corbo, J. C.; Guengerich, F. P. Human Cytochrome P450 27C1 Catalyzes 3,4-Desaturation of Retinoids. FEBS Lett. 2016, 590, 1304-1312.

(35) Belin, P.; Le Du, M. H.; Fielding, A.; Lequin, O.; Jacquet, M.; Charbonnier, J.-B.; Lecoq, A.; Thai, R.; Courçon, M.; Masson, C.; Dugave, C.; Genet, R.; Pernodet, J.-L.; Gondry, M. Identification and Structural Basis of the Reaction Catalyzed by CYP121, an Essential Cytochrome P450 in Mycobacterium tuberculosis. Proc. Natl. Acad. Sci. U.S.A. 2009, 106, 7426-7431. 
(36) Omura, T.; Sato, R. The Carbon Monoxide-Binding Pigment of Liver Microsomes: I. Evidence for its Hemoprotein Nature. J. Biol. Chem. 1964, 239, 2370-2378.

(37) Nelson, D. R. The Cytochrome P450 Homepage. Hum. Genet. 2009, 4, 59.

(38) Chen, M. M.; Coelho, P. S.; Arnold, F. H. Utilizing Terminal Oxidants to Achieve P450-Catalyzed Oxidation of Methane. Adv. Synth. Catal. 2012, 354, 964-968.

(39) Vallee, B. L.; Williams, R. J. Metalloenzymes: The Entatic Nature of Their Active Sites. Proc. Natl. Acad. Sci. U.S.A. 1968, 59, 498-505.

(40) Sevrioukova, I. F.; Li, H.; Zhang, H.; Peterson, J. A.; Poulos, T. L. Structure of a Cytochrome P450-Redox Partner Electron-Transfer Complex. Proc. Natl. Acad. Sci. U.S.A. 1999, 96, 1863-1868.

(41) Sevrioukova, I.; Shaffer, C.; Ballou, D. P.; Peterson, J. A. Equilibrium and Transient State Spectrophotometric Studies of the Mechanism of Reduction of the Flavoprotein Domain of P450BM-3. Biochemistry 1996, 35, 7058-7068.

(42) Daff, S. N.; Chapman, S. K.; Holt, R. A.; Govindaraj, S.; Poulos, T. L.; Munro, A. W. Redox Control of the Catalytic Cycle of Flavocytochrome P-450 BM3. Biochemistry 1997, 36, 13816-13823.

(43) Hlavica, P. Control by Substrate of the Cytochrome P450-Dependent Redox Machinery: Mechanistic Insights. Curr. Drug Metab. 2007, 8, 594-611.

(44) Zangar, R. C.; Davydov, D. R.; Verma, S. Mechanisms That Regulate Production of Reactive Oxygen Species by Cytochrome P450. Toxicol. Appl. Pharmacol. 2004, 199, 316-331.

(45) Baek, H. K.; Van Wart, H. E. Elementary Steps in the Formation of Horseradish Peroxidase Compound I: Direct Observation of Compound 0, a New Intermediate with a Hyperporphyrin Spectrum. Biochemistry 1989, 28, 5714-5719.

(46) Waskell, L.; Kim, J.-J. P. Electron Transfer Partners of Cytochrome P450. In Cytochrome P450; Springer, Cham: Switzerland, 2015, p 33-68.

(47) Su, M.; Chakraborty, S.; Osawa, Y.; Zhang, H. Cryo-EM Reveals the Architecture of the Dimeric Cytochrome P450 CYP102A1 Enzyme and Conformational Changes Required for Redox Partner Recognition. J. Biol. Chem. 2020, 295, 1637-1645.

(48) Yeom, H.; Sligar, S. G.; Li, H.; Poulos, T. L.; Fulco, A. J. The Role of Thr268 in Oxygen Activation of Cytochrome P450BM-3. Biochemistry 1995, 34, 14733-14740.

(49) Raag, R.; Martinis, S. A.; Sligar, S. G.; Poulos, T. L. Crystal Structure of the Cytochrome P-450CAM Active Site Mutant Thr252Ala. Biochemistry 1991, 30, 11420-11429.

(50) Li, H.; Poulos, T. L. Modeling Protein-Substrate Interactions in the Heme Domain of Cytochrome P450BM-3. Acta Crystallogr., Sect. D: Biol. Crystallogr. 1995, 51, 21-32.

(51) Shoji, O.; Fujishiro, T.; Nishio, K.; Kano, Y.; Kimoto, H.; Chien, S.-C.; Onoda, H.; Muramatsu, A.; Tanaka, S.; Hori, A.; Sugimoto, H.; Shiro, Y.; Watanabe, Y. A Substrate-BindingState Mimic of $\mathrm{H}_{2} \mathrm{O}_{2}$-Dependent Cytochrome P450 Produced by One-Point Mutagenesis and Peroxygenation of Non-Native Substrates. Catal. Sci. Technol. 2016, 6, 5806-5811.

(52) Dawson, J. H.; Sono, M. Cytochrome P-450 and Chloroperoxidase: ThiolateLigated Heme Enzymes. Spectroscopic Determination of Their Active-Site Structures and Mechanistic Implications of Thiolate Ligation. Chem. Rev. 1987, 87, 1255-1276.

(53) Green, M. T. Evidence for Sulfur-Based Radicals in Thiolate Compound I Intermediates. J. Am. Chem. Soc. 1999, 121, 7939-7940.

(54) Yosca, T. H.; Rittle, J.; Krest, C. M.; Onderko, E. L.; Silakov, A.; Calixto, J. C.; Behan, R. K.; Green, M. T. Iron(IV)hydroxide $\mathrm{pKa}$ and the Role of Thiolate Ligation in C-H Bond Activation by Cytochrome P450. Science 2013, 342, 825. 
(55) Groves, J. T. Key Elements of the Chemistry of Cytochrome P-450: The Oxygen Rebound Mechanism. J. Chem. Educ. 1985, 62, 928-931.

(56) Green, M. T.; Dawson, J. H.; Gray, H. B. Oxoiron(IV) in Chloroperoxidase Compound II is Basic: Implications for P450 Chemistry. Science 2004, 304, 1653-1656.

(57) Green, M. T. C-H Bond Activation in Heme Proteins: The Role of Thiolate Ligation in Cytochrome P450. Curr. Opin. Chem. Biol. 2009, 13, 84-88.

(58) Krest, C. M.; Silakov, A.; Rittle, J.; Yosca, T. H.; Onderko, E. L.; Calixto, J. C.; Green, M. T. Significantly Shorter Fe-S Bond in Cytochrome P450-I is Consistent with Greater Reactivity Relative to Chloroperoxidase. Nat. Chem. 2015, 7, 696-702.

(59) Onderko, E. L.; Silakov, A.; Yosca, T. H.; Green, M. T. Characterization of a Selenocysteine-Ligated P450 Compound I Reveals Direct Link Between Electron Donation and Reactivity. Nat. Chem. 2017, 9, 623-628.

(60) Basran, J.; Booth, E. S.; Lee, M.; Handa, S.; Raven, E. L. Analysis of Reaction Intermediates in Tryptophan 2,3-Dioxygenase: A Comparison with Indoleamine 2,3-Dioxygenase. Biochemistry 2016, 55, 6743-6750.

(61) Geng, J.; Weitz, A. C.; Dornevil, K.; Hendrich, M. P.; Liu, A. Kinetic and Spectroscopic Characterization of the Catalytic Ternary Complex of Tryptophan 2,3-Dioxygenase. Biochemistry 2020, 59, 2813-2822.

(62) Davies, H. M. L.; Manning, J. R. Catalytic C-H Functionalization by Metal Carbenoid and Nitrenoid Insertion. Nature 2008, 451, 417-424.

(63) Hoffmann, R. Building Bridges Between Inorganic and Organic Chemistry (Nobel Lecture). Angew. Chem. Int. Ed. 1982, 21, 711-724.

(64) Coelho, P. S.; Brustad, E. M.; Kannan, A.; Arnold, F. H. Olefin Cyclopropanation via Carbene Transfer Catalyzed by Engineered Cytochrome P450 Enzymes. Science 2013, 339, 307-310.

(65) Coelho, P. S.; Wang, Z. J.; Ener, M. E.; Baril, S. A.; Kannan, A.; Arnold, F. H.; Brustad, E. M. A Serine-Substituted P450 Catalyzes Highly Efficient Carbene Transfer to Olefins in vivo. Nat. Chem. Biol. 2013, 9, 485-487.

(66) Knight, A. M.; Kan, S. B. J.; Lewis, R. D.; Brandenberg, O. F.; Chen, K.; Arnold, F. H. Diverse Engineered Heme Proteins Enable Stereodivergent Cyclopropanation of Unactivated Alkenes. ACS Cent. Sci. 2018, 4, 372-377.

(67) Brandenberg, O. F.; Prier, C. K.; Chen, K.; Knight, A. M.; Wu, Z.; Arnold, F. H. Stereoselective Enzymatic Synthesis of Heteroatom-Substituted Cyclopropanes. ACS Catal. 2018, $8,2629-2634$.

(68) Chen, K.; Zhang, S.-Q.; Brandenberg, O. F.; Hong, X.; Arnold, F. H. Alternate Heme Ligation Steers Activity and Selectivity in Engineered Cytochrome P450-Catalyzed Carbene-Transfer Reactions. J. Am. Chem. Soc. 2018, 140, 16402-16407.

(69) Brandenberg, O. F.; Chen, K.; Arnold, F. H. Directed Evolution of a Cytochrome P450 Carbene Transferase for Selective Functionalization of Cyclic Compounds. J. Am. Chem. Soc. 2019, 141, 8989-8995.

(70) Bordeaux, M.; Tyagi, V.; Fasan, R. Highly Diastereoselective and Enantioselective Olefin Cyclopropanation Using Engineered Myoglobin-Based Catalysts. Angew. Chem. Int. Ed. 2015, 54, 1744-1748.

(71) Tinoco, A.; Steck, V.; Tyagi, V.; Fasan, R. Highly Diastereo- and Enantioselective Synthesis of Trifluoromethyl-Substituted Cyclopropanes via Myoglobin-Catalyzed Transfer of Trifluoromethylcarbene. J. Am. Chem. Soc. 2017, 139, 5293-5296. 
(72) Chandgude, A. L.; Fasan, R. Highly Diastereo- and Enantioselective Synthesis of Nitrile-Substituted Cyclopropanes by Myoglobin-Mediated Carbene Transfer Catalysis. Angew. Chem. Int. Ed. 2018, 57, 15852-15856.

(73) Chandgude, A. L.; Ren, X.; Fasan, R. Stereodivergent Intramolecular Cyclopropanation Enabled by Engineered Carbene Transferases. J. Am. Chem. Soc. 2019, 141, 9145-9150.

(74) Vargas, D. A.; Khade, R. L.; Zhang, Y.; Fasan, R. Biocatalytic Strategy for Highly Diastereo- and Enantioselective Synthesis of 2,3-Dihydrobenzofuran-Based Tricyclic Scaffolds. Angew. Chem. Int. Ed. 2019, 58, 10148-10152.

(75) Carminati, D. M.; Fasan, R. Stereoselective Cyclopropanation of ElectronDeficient Olefins with a Cofactor Redesigned Carbene Transferase Featuring Radical Reactivity. ACS Catal. 2019, 9, 9683-9697.

(76) Ren, X.; Chandgude, A. L.; Fasan, R. Highly Stereoselective Synthesis of Fused Cyclopropane- $\gamma$-Lactams via Biocatalytic Iron-Catalyzed Intramolecular Cyclopropanation. ACS Catal. 2020, 10, 2308-2313.

(77) Renata, H.; Wang, Z. J.; Kitto, R. Z.; Arnold, F. H. P450-Catalyzed Asymmetric Cyclopropanation of Electron-Deficient Olefins Under Aerobic Conditions. Catal. Sci. Technol. 2014, 4, 3640-3643.

(78) Wittmann, B. J.; Knight, A. M.; Hofstra, J. L.; Reisman, S. E.; Jennifer Kan, S. B.; Arnold, F. H. Diversity-Oriented Enzymatic Synthesis of Cyclopropane Building Blocks. ACS Catal. 2020, 10, 7112-7116.

(79) Chen, K.; Huang, X.; Kan, S. B. J.; Zhang, R. K.; Arnold, F. H. Enzymatic Construction of Highly Strained Carbocycles. Science 2018, 360, 71-75.

(80) Chen, K.; Arnold, F. H. Engineering Cytochrome P450s for Enantioselective Cyclopropenation of Internal Alkynes. J. Am. Chem. Soc. 2020, 142, 6891-6895.

(81) Wang, Z. J.; Peck, N. E.; Renata, H.; Arnold, F. H. Cytochrome P450-Catalyzed Insertion of Carbenoids into N-H Bonds. Chem. Sci. 2014, 5, 598-601.

(82) Sreenilayam, G.; Fasan, R. Myoglobin-Catalyzed Intermolecular Carbene N-H Insertion with Arylamine Substrates. Chem Comm 2015, 51, 1532-1534.

(83) Tyagi, V.; Bonn, R. B.; Fasan, R. Intermolecular Carbene S-H Insertion Catalysed by Engineered Myoglobin-Based Catalysts. Chem. Sci. 2015, 6, 2488-2494.

(84) Kan, S. B. J.; Lewis, R. D.; Chen, K.; Arnold, F. H. Directed Evolution of Cytochrome $c$ for Carbon-Silicon Bond Formation: Bringing Silicon to Life. Science 2016, 354, 1048-1051.

(85) Kan, S. B. J.; Huang, X. Y.; Gumulya, Y.; Chen, K.; Arnold, F. H. Genetically Programmed Chiral Organoborane Synthesis. Nature 2017, 552, 132-+.

(86) Chen, K.; Huang, X.; Zhang, S.-Q.; Zhou, A. Z.; Kan, S. B. J.; Hong, X.; Arnold, F. H. Engineered Cytochrome $c$-Catalyzed Lactone-Carbene B-H Insertion. Synlett 2019, 30, 378382.

(87) Huang, X.; Garcia-Borràs, M.; Miao, K.; Kan, S. B. J.; Zutshi, A.; Houk, K. N.; Arnold, F. H. A Biocatalytic Platform for Synthesis of Chiral $\alpha$-Trifluoromethylated Organoborons. ACS Cent. Sci. 2019, 5, 270-276.

(88) Zhang, R. K.; Chen, K.; Huang, X.; Wohlschlager, L.; Renata, H.; Arnold, F. H. Enzymatic Assembly of Carbon-Carbon Bonds via Iron-Catalysed $s p^{3} \mathrm{C}-\mathrm{H}$ Functionalization. Nature 2019, 565, 67-72. 
(89) Zhang, J.; Huang, X.; Zhang, R. K.; Arnold, F. H. Enantiodivergent $\alpha$-Amino C-H Fluoroalkylation Catalyzed by Engineered Cytochrome P450s. J. Am. Chem. Soc. 2019, 141, 97989802.

(90) Zhou, A. Z.; Chen, K.; Arnold, F. H. Enzymatic Lactone-Carbene C-H Insertion to Build Contiguous Chiral Centers. ACS Catal. 2020, 10, 5393-5398.

(91) Svastits, E. W.; Dawson, J. H.; Breslow, R.; Gellman, S. H. Functionalized Nitrogen Atom Transfer Catalyzed by Cytochrome P-450. J. Am. Chem. Soc. 1985, 107, 64276428.

(92) McIntosh, J. A.; Coelho, P. S.; Farwell, C. C.; Wang, Z. J.; Lewis, J. C.; Brown, T. R.; Arnold, F. H. Enantioselective Intramolecular C-H Amination Catalyzed by Engineered Cytochrome P450 Enzymes In Vitro and In Vivo. Angew. Chem. Int. Ed. 2013, 52, 9309-9312.

(93) Singh, R.; Bordeaux, M.; Fasan, R. P450-Catalyzed Intramolecular $s p^{3} \mathrm{C}-\mathrm{H}$ Amination with Arylsulfonyl Azide Substrates. ACS Catal. 2014, 4, 546-552.

(94) Prier, C. K.; Zhang, R. J. K.; Buller, A. R.; Brinkmann-Chen, S.; Arnold, F. H. Enantioselective, Intermolecular Benzylic C-H Amination Catalysed by an Engineered Iron-haem Enzyme. Nat. Chem. 2017, 9, 629-634.

(95) Farwell, C. C.; Zhang, R. K.; McIntosh, J. A.; Hyster, T. K.; Arnold, F. H. Enantioselective Enzyme-Catalyzed Aziridination Enabled by Active-Site Evolution of a Cytochrome P450. ACS Cent. Sci. 2015, 1, 89-93.

(96) Sabir, S.; Kumar, G.; Jat, J. L. O-Substituted Hydroxyl Amine Reagents: An Overview of Recent Synthetic Advances. Org. Biomol. Chem. 2018, 16, 3314-3327.

(97) Tsutsumi, H.; Katsuyama, Y.; Izumikawa, M.; Takagi, M.; Fujie, M.; Satoh, N.; Shin-ya, K.; Ohnishi, Y. Unprecedented Cyclization Catalyzed by a Cytochrome P450 in Benzastatin Biosynthesis. J. Am. Chem. Soc. 2018, 140, 6631-6639.

(98) Cho, I.; Prier, C. K.; Jia, Z.-J.; Zhang, R. K.; Görbe, T.; Arnold, F. H. Enantioselective Aminohydroxylation of Styrenyl Olefins Catalyzed by an Engineered Hemoprotein. Angew. Chem. Int. Ed. 2019, 58, 3138-3142.

(99) Jia, Z.-J.; Gao, S.; Arnold, F. H. Enzymatic Primary Amination of Benzylic and Allylic C(sp3)-H Bonds. J. Am. Chem. Soc. 2020, 142, 10279-10283.

(100) Moore, E. J.; Fasan, R. Effect of Proximal Ligand Substitutions on the Carbene and Nitrene Transferase Activity of Myoglobin. Tetrahedron 2019, 75, 2357-2363.

(101) Green, A. P.; Hayashi, T.; Mittl, P. R. E.; Hilvert, D. A Chemically Programmed Proximal Ligand Enhances the Catalytic Properties of a Heme Enzyme. J. Am. Chem. Soc. 2016, $138,11344-11352$.

(102) Pott, M.; Hayashi, T.; Mori, T.; Mittl, P. R. E.; Green, A. P.; Hilvert, D. A Noncanonical Proximal Heme Ligand Affords an Efficient Peroxidase in a Globin Fold. J. Am. Chem. Soc. 2018, 140, 1535-1543.

(103) Renata, H.; Lewis, R. D.; Sweredoski, M. J.; Moradian, A.; Hess, S.; Wang, Z. J.; Arnold, F. H. Identification of Mechanism-Based Inactivation in P450-Catalyzed Cyclopropanation Facilitates Engineering of Improved Enzymes. J. Am. Chem. Soc. 2016, 138, 12527-12533.

(104) Farwell, C. C.; McIntosh, J. A.; Hyster, T. K.; Wang, Z. J.; Arnold, F. H. Enantioselective Imidation of Sulfides via Enzyme-Catalyzed Intermolecular Nitrogen-Atom Transfer. J. Am. Chem. Soc. 2014, 136, 8766-8771.

(105) Fenton, H. J. H. LXXIII.- Oxidation of Tartaric Acid in Presence of Iron. J. Chem. Soc., Trans. 1894, 65, 899-910. 
(106) Bryant, J. D.; Wilson, J. T. Fenton's in-situ Reagent Chemical Oxidation of Hydrocarbon Contamination in Soil and Groundwater. Remediation 1999, 9, 13-25.

(107) Groves, J. T.; Van der Puy, M. Stereospecific Aliphatic Hydroxylation by IronHydrogen Peroxide. Evidence for a Stepwise Srocess. J. Am. Chem. Soc. 1976, 98, 5290-5297.

(108) Groves, J. T. High-Valent Iron in Chemical and Biological Oxidations. J. Inorg. Biochem. 2006, 100, 434-447.

(109) Loegager, T.; Holcman, J.; Sehested, K.; Pedersen, T. Oxidation of Ferrous Ions by Ozone in Acidic Solutions. Inorg. Chem. 1992, 31, 3523-3529.

(110) Pestovsky, O.; Bakac, A. Reactivity of Aqueous Fe(IV) in Hydride and Hydrogen Atom Transfer Reactions. J. Am. Chem. Soc. 2004, 126, 13757-13764.

(111) Barton, D. H. R.; Gastiger, M. J.; Motherwell, W. B. A New Procedure for the Oxidation of Saturated Hydrocarbons. J. Chem. Soc., Chem. Commun. 1983, 41-43.

(112) Barton, D. H. R.; Doller, D. The Selective Functionalization of Saturated Hydrocarbons: Gif Chemistry. Acc. Chem. Res. 1992, 25, 504-512.

(113) Stavropoulos, P.; Çelenligil-Çetin, R.; Tapper, A. E. The Gif Paradox. Acc. Chem. Res. 2001, 34, 745-752.

(114) Hegg, E. L.; Jr, L. Q. The 2-His-1-Carboxylate Facial Triad - An Emerging Structural Motif in Mononuclear Non-Heme Iron(II) Enzymes. Eur. J. Biochem. 1997, 250, 625629.

(115) Koehntop, K. D.; Emerson, J. P.; Que, L., Jr. The 2-His-1-Carboxylate Facial Triad: A Versatile Platform for Dioxygen Activation by Mononuclear Non-Heme Iron(II) Enzymes. $J$. Biol. Inorg. Chem. 2005, 10, 87-93.

(116) Kal, S.; Que, L. Dioxygen Activation by Nonheme Iron Enzymes with the 2-His1-Carboxylate Facial Triad That Generate High-Valent Oxoiron Oxidants. J. Biol. Inorg. Chem. 2017, 22, 339-365.

(117) Lipscomb, J. D. Mechanism of Extradiol Aromatic Ring-Cleaving Dioxygenases. Curr. Opin. Struct. Biol. 2008, 18, 644-649.

(118) Barry, S. M.; Challis, G. L. Mechanism and Catalytic Diversity of Rieske NonHeme Iron-Dependent Oxygenases. ACS Catal. 2013, 3, 2362-2370.

(119) Martinez, S.; Hausinger, R. P. Catalytic Mechanisms of Fe(II)- and 2-Oxoglutaratedependent Oxygenases. J. Biol. Chem. 2015, 290, 20702-20711.

(120) Fitzpatrick, P. F. Mechanism of Aromatic Amino Acid Hydroxylation. Biochemistry 2003, 42, 14083-14091.

(121) Baldwin, J. E.; Bradley, M. Isopenicillin N Synthase: Mechanistic Studies. Chem. Rev. 1990, 90, 1079-1088.

(122) Tamanaha, E.; Zhang, B.; Guo, Y.; Chang, W. C.; Barr, E. W.; Xing, G.; St Clair, J.; Ye, S.; Neese, F.; Bollinger, J. M., Jr.; Krebs, C. Spectroscopic Evidence for the Two C-HCleaving Intermediates of Aspergillus nidulans Isopenicillin N Synthase. J. Am. Chem. Soc. 2016, $138,8862-8874$.

(123) Wang, C.; Chang, W. C.; Guo, Y. S.; Huang, H.; Peck, S. C.; Pandelia, M. E.; Lin, G. M.; Liu, H. W.; Krebs, C.; Bollinger, J. M. Evidence that the Fosfomycin-Producing Epoxidase, HppE, is a Non-Heme-Iron Peroxidase. Science 2013, 342, 991-995.

(124) Peck, S. C.; Wang, C.; Dassama, L. M. K.; Zhang, B.; Guo, Y.; Rajakovich, L. J.; Bollinger, J. M.; Krebs, C.; van der Donk, W. A. O-H Activation by an Unexpected Ferryl Intermediate during Catalysis by 2-Hydroxyethylphosphonate Dioxygenase. J. Am. Chem. Soc. 2017, 139, 2045-2052. 
(125) Born, D. A.; Ulrich, E. C.; Ju, K.-S.; Peck, S. C.; van der Donk, W. A.; Drennan, C. L. Structural Basis for Methylphosphonate Biosynthesis. Science 2017, 358, 1336-1339.

(126) Mirica, L. M.; Klinman, J. P. The Nature of $\mathrm{O}_{2}$ Activation by the Ethylene-Forming Enzyme 1-Aminocyclopropane-1-Carboxylic Acid Oxidase. Proc. Natl. Acad. Sci. U.S.A. 2008, 105, 1814-1819.

(127) Puri, M.; Que, L. Toward the Synthesis of More Reactive $S=2$ Non-Heme Oxoiron(IV) Complexes. Acc. Chem. Res. 2015, 48, 2443-2452.

(128) Oloo, W. N.; Que, L. Bioinspired Nonheme Iron Catalysts for C-H and C $=\mathrm{C}$ Bond Oxidation: Insights into the Nature of the Metal-Based Oxidants. Acc. Chem. Res. 2015, 48, 26122621.

(129) Kal, S.; Xu, S.; Que Jr., L. Bio-inspired Nonheme Iron Oxidation Catalysis: Involvement of Oxoiron(V) Oxidants in Cleaving Strong C-H Bonds. Angew. Chem. Int. Ed. 2020, 59, 7332-7349.

(130) Roach, R. L.; Clifton, I. J.; Hensgens, C. M. H.; Shibata, N.; Schofield, C. J.; Hajdu, J.; Baldwin, J. E. Structure of Isopenicillin $N$ Synthase Complexed with Substrate and the Mechanism of Penicillin Formation. Nature 1997, 387.

(131) Zhang, Z.; Ren, J.-s.; Harlos, K.; McKinnon, C. H.; Clifton, I. J.; Schofield, C. J. Crystal Structure of a Clavaminate Synthase-Fe(II)-2-Oxoglutarate-Substrate-NO Complex: Evidence for Metal Centered Rearrangements. FEBS Lett. 2002, 517, 7-12.

(132) Mitchell, A. J.; Zhu, Q.; Maggiolo, A. O.; Ananth, N. R.; Hillwig, M. L.; Liu, X.; Boal, A. K. Structural Basis for Halogenation by Iron- and 2-Oxo-Glutarate-Dependent Enzyme WelO5. Nat. Chem. Biol. 2016, 12, 636-640.

(133) Bassan, A.; Blomberg, M. R. A.; Siegbahn, P. E. M. Mechanism of Dioxygen Cleavage in Tetrahydrobiopterin-Dependent Amino Acid Hydroxylases. Chem. Eur. J. 2003, 9 , 106-115.

(134) Olsson, E.; Martinez, A.; Teigen, K.; Jensen, V. R. Formation of the Iron-Oxo Hydroxylating Species in the Catalytic Cycle of Aromatic Amino Acid Hydroxylases. Chem. Eur. J. 2011, 17, 3746-3758.

(135) Andreas Andersen, O.; Flatmark, T.; Hough, E. Crystal Structure of the Ternary Complex of the Catalytic Domain of Human Phenylalanine Hydroxylase with Tetrahydrobiopterin and 3-(2-Thienyl)-1-alanine, and its Implications for the Mechanism of Catalysis and Substrate Activation. J. Mol. Biol. 2002, 320, 1095-1108.

(136) Karlsson, A.; Parales, J. V.; Parales, R. E.; Gibson, D. T.; Eklund, H.; Ramaswamy, S. Crystal Structure of Naphthalene Dioxygenase: Side-on Binding of Dioxygen to Iron. Science 2003, 299, 1039-1042.

(137) Ashikawa, Y.; Fujimoto, Z.; Usami, Y.; Inoue, K.; Noguchi, H.; Yamane, H.; Nojiri, H. Structural Insight Into the Substrate- and Dioxygen-Binding Manner in the Catalytic Cycle of Rieske Nonheme Iron Oxygenase System, Carbazole 1,9a-Dioxygenase. BMC Struct. Biol. 2012, 12, 15.

(138) Kovaleva, E. G.; Lipscomb, J. D. Crystal Structures of Fe(II) Dioxygenase Superoxo, Alkylperoxo, and Bound Product Intermediates. Science 2007, 316, 453-457.

(139) Wang, Y.; Liu, K. F.; Yang, Y.; Davis, I.; Liu, A. Observing 3Hydroxyanthranilate-3,4-Dioxygenase in Action Through a Crystalline Lens. Proc. Natl. Acad. Sci. U.S.A. 2020, 117, 19720-19730.

(140) Krebs, C.; Galonić Fujimori, D.; Walsh, C. T.; Bollinger, J. M., Jr. Non-Heme Fe(IV)-Oxo Intermediates. Acc. Chem. Res. 2007, 40, 484-493. 
(141) Herr, C. Q.; Hausinger, R. P. Amazing Diversity in Biochemical Roles of Fe(II)/2Oxoglutarate Oxygenases. Trends Biochem. Sci. 2018, 43, 517-532.

(142) Price, J. C.; Barr, E. W.; Tirupati, B.; Bollinger, J. M., Jr.; Krebs, C. The First Direct Characterization of a High-Valent Iron Intermediate in the Reaction of an $\alpha$-KetoglutarateDependent Dioxygenase: A High-Spin Fe(IV) Complex in Taurine/ $\alpha$-Ketoglutarate Dioxygenase (TauD) from Escherichia coli. Biochemistry 2003, 42, 7497-7508.

(143) Price, J. C.; Barr, E. W.; Glass, T. E.; Krebs, C.; Bollinger, J. M., Jr. Evidence for Hydrogen Abstraction from $\mathrm{C} 1$ of Taurine by the High-Spin Fe(IV) Intermediate Detected During Oxygen Activation by Taurine: $\alpha$-Ketoglutarate Dioxygenase (TauD). J. Am. Chem. Soc. 2003, $125,13008-13009$.

(144) Hoffart, L. M.; Barr, E. W.; Guyer, R. B.; Bollinger, J. M., Jr.; Krebs, C. Direct Spectroscopic Detection of a C-H-Cleaving High-Spin Fe(IV) Complex in a Prolyl-4Hydroxylase. Proc. Natl. Acad. Sci. U.S.A. 2006, 103, 14738-14743.

(145) Galonić, D. P.; Barr, E. W.; Walsh, C. T.; Bollinger, J. M., Jr.; Krebs, C. Two Interconverting $\mathrm{Fe}(\mathrm{IV})$ Intermediates in Aliphatic Chlorination by the Halogenase CytC3. Nat. Chem. Biol. 2007, 3, 113-116.

(146) Matthews, M. L.; Krest, C. M.; Barr, E. W.; Vaillancourt, F. H.; Walsh, C. T.; Green, M. T.; Krebs, C.; Bollinger, J. M., Jr. Substrate-Triggered Formation and Remarkable Stability of the C-H Bond-Cleaving Chloroferryl Intermediate in the Aliphatic Halogenase, SyrB2. Biochemistry 2009, 48, 4331-4343.

(147) Grzyska, P. K.; Appelman, E. H.; Hausinger, R. P.; Proshlyakov, D. A. Insight Into the Mechanism of an Iron Dioxygenase by Resolution of Steps Following the $\mathrm{Fe}(\mathrm{IV})=\mathrm{O}$ Species. Proc. Natl. Acad. Sci. U.S.A. 2010, 107, 3982-3987.

(148) Chang, W.-c.; Guo, Y.; Wang, C.; Butch, S. E.; Rosenzweig, A. C.; Boal, A. K.; Krebs, C.; Bollinger, J. M., Jr. Mechanism of the C5 Stereoinversion Reaction in the Biosynthesis of Carbapenem Antibiotics. Science 2014, 343, 1140-1144.

(149) Mitchell, A. J.; Dunham, N. P.; Martinie, R. J.; Bergman, J. A.; Pollock, C. J.; Hu, K.; Allen, B. D.; Chang, W. C.; Silakov, A.; Bollinger, J. M., Jr.; Krebs, C.; Boal, A. K. Visualizing the Reaction Cycle in an Iron(II)- and 2-(Oxo)-glutarate-Dependent Hydroxylase. J. Am. Chem. Soc. 2017, 139, 13830-13836.

(150) Pan, J.; Bhardwaj, M.; Zhang, B.; Chang, W. c.; Schardl, C. L.; Krebs, C.; Grossman, R. B.; Bollinger, J. M., Jr. Installation of the Ether Bridge of Lolines by the Iron- and 2-Oxoglutarate-Dependent Oxygenase, LolO: Regio- and Stereochemistry of Sequential Hydroxylation and Oxacyclization Reactions. Biochemistry 2018, 57, 2074-2083.

(151) Pan, J.; Wenger, E. S.; Matthews, M. L.; Pollock, C. J.; Bhardwaj, M.; Kim, A. J.; Allen, B. D.; Grossman, R. B.; Krebs, C.; Bollinger, J. M. Evidence for Modulation of Oxygen Rebound Rate in Control of Outcome by Iron(II)- and 2-Oxoglutarate-Dependent Oxygenases. $J$. Am. Chem. Soc. 2019, 141, 15153-15165.

(152) Li, J.; Liao, H.-J.; Tang, Y.; Huang, J.-L.; Cha, L.; Lin, T.-S.; Lee, J. L.; Kurnikov, I. V.; Kurnikova, M. G.; Chang, W.-c.; Chan, N.-L.; Guo, Y. Epoxidation Catalyzed by the Nonheme Iron(II)- and 2-Oxoglutarate-Dependent Oxygenase, AsqJ: Mechanistic Elucidation of Oxygen Atom Transfer by a Ferryl Intermediate. J. Am. Chem. Soc. 2020, 142, 6268-6284.

(153) Blasiak, L. C.; Vaillancourt, F. H.; Walsh, C. T.; Drennan, C. L. Crystal Structure of the Non-Haem Iron Halogenase SyrB2 in Syringomycin Biosynthesis. Nature 2006, 440, 368371. 
(154) Matthews, M. L.; Neumann, C. S.; Miles, L. A.; Grove, T. L.; Booker, S. J.; Krebs, C.; Walsh, C. T.; Bollinger, J. M., Jr. Substrate Positioning Controls the Partition Between Halogenation and Hydroyxlation in the Aliphatic Halogenase, SyrB2. Proc. Natl. Acad. Sci. U.S.A. 2009, 106, 17723-17728.

(155) Wong, S. D.; Srnec, M.; Matthews, M. L.; Liu, L. V.; Kwak, Y.; Park, K.; Bell, C. B., 3rd; Alp, E. E.; Zhao, J.; Yoda, Y.; Kitao, S.; Seto, M.; Krebs, C.; Bollinger, J. M., Jr.; Solomon, E. I. Elucidation of the $\mathrm{Fe}(\mathrm{IV})=\mathrm{O}$ Intermediate in the Catalytic Cycle of the Halogenase SyrB2. Nature 2013, 499, 320-323.

(156) Martinie, R. J.; Livada, J.; Chang, W.-c.; Green, M. T.; Krebs, C.; Bollinger, J. M., Jr.; Silakov, A. Experimental Correlation of Substrate Position with Reaction Outcome in the Aliphatic Halogenase, SyrB2. J. Am. Chem. Soc. 2015, 137, 6912-6919.

(157) Dunham, N. P.; Chang, W.-c.; Mitchell, A. J.; Martinie, R. J.; Zhang, B.; Bergman, J. A.; Rajakovich, L. J.; Wang, B.; Silakov, A.; Krebs, C.; Boal, A. K.; Bollinger, J. M., Jr. Two Distinct Mechanisms for C-C Desaturation by Iron(II)- and 2-(Oxo)glutarate-Dependent Oxygenases: Importance of Alpha-Heteroatom Assistance. J. Am. Chem. Soc. 2018, 140, 71167126.

(158) Ushimaru, R.; Ruszczycky, M. W.; Liu, H.-w. Changes in Regioselectivity of H Atom Abstraction during the Hydroxylation and Cyclization Reactions Catalyzed by Hyoscyamine 6ß-Hydroxylase. J. Am. Chem. Soc. 2019, 141, 1062-1066.

(159) Chang, W.-c.; Yang, Z.-J.; Tu, Y.-H.; Chien, T.-C. Reaction Mechanism of a Nonheme Iron Enzyme Catalyzed Oxidative Cyclization via $\mathrm{C}-\mathrm{C}$ Bond Formation. Org. Lett. 2019, 21, 228-232.

(160) Borowski, T.; de Marothy, S.; Broclawik, E.; Schofield, C. J.; Siegbahn, P. E. M. Mechanism for Cyclization Reaction by Clavaminic Acid Synthase. Insights From Modeling Studies. Biochemistry 2007, 46, 3682-3691.

(161) Dunham, N. P.; Del Río Pantoja, J. M.; Zhang, B.; Rajakovich, L. J.; Allen, B. D.; Krebs, C.; Boal, A. K.; Bollinger, J. M. Hydrogen Donation but not Abstraction by a Tyrosine (Y68) During Endoperoxide Installation by Verruculogen Synthase (FtmOx1). J. Am. Chem. Soc. 2019, 141, 9964-9979.

(162) Liu, W.; Groves, J. T. Manganese Porphyrins Catalyze Selective C-H Bond Halogenations. J. Am. Chem. Soc. 2010, 132, 12847-12849.

(163) Liu, W.; Huang, X.; Cheng, M.-J.; Nielsen, R. J.; Goddard, W. A.; Groves, J. T. Oxidative Aliphatic C-H Fluorination with Fluoride Ion Catalyzed by a Manganese Porphyrin. Science 2012, 337, 1322-1325.

(164) Schmidt, V. A.; Quinn, R. K.; Brusoe, A. T.; Alexanian, E. J. Site-Selective Aliphatic C-H Bromination Using N-Bromoamides and Visible Light. J. Am. Chem. Soc. 2014, 136, 14389-14392.

(165) Liu, W.; Groves, J. T. Manganese Catalyzed C-H Halogenation. Acc. Chem. Res. 2015, 48, 1727-1735.

(166) Margrey, K. A.; Czaplyski, W. L.; Nicewicz, D. A.; Alexanian, E. J. A General Strategy for Aliphatic C-H Functionalization Enabled by Organic Photoredox Catalysis. J. Am. Chem. Soc. 2018, 140, 4213-4217.

(167) Matthews, M. L.; Chang, W. C.; Layne, A. P.; Miles, L. A.; Krebs, C.; Bollinger, J. M., Jr. Direct Nitration and Azidation of Aliphatic Carbons by an Iron-Dependent Halogenase. Nat. Chem. Biol. 2014, 10, 209-215. 
(168) Neugebauer, M. E.; Sumida, K. H.; Pelton, J. G.; McMurry, J. L.; Marchand, J. A.; Chang, M. C. Y. A family of Radical Halogenases for the Engineering of Amino-Acid-Based Products. Nat. Chem. Biol. 2019, 15, 1009-1016.

(169) Kim, C. Y.; Mitchell, A. J.; Glinkerman, C. M.; Li, F.-S.; Pluskal, T.; Weng, J.-K. The Chloroalkaloid (-)-Acutumine is Biosynthesized via a Fe(II)- and 2-Oxoglutarate-Dependent Halogenase in Menispermaceae Plants. Nat. Commun. 2020, 11, 1867.

(170) Jewett, J. C.; Bertozzi, C. R. Cu-Free Click Cycloaddition Reactions in Chemical Biology. Chem. Soc. Rev. 2010, 39, 1272-1279.

(171) Mitchell, A. J.; Dunham, N. P.; Bergman, J. A.; Wang, B.; Zhu, Q.; Chang, W.-c.; Liu, X.; Boal, A. K. Structure-Guided Reprogramming of a Hydroxylase to Halogenate its Small Molecule Substrate. Biochemistry 2017, 56, 441-444.

(172) Davidson, M.; McNamee, M.; Fan, R.; Guo, Y.; Chang, W.-c. Repurposing Nonheme Iron Hydroxylases To Enable Catalytic Nitrile Installation through an Azido Group Assistance. J. Am. Chem. Soc. 2019, 141, 3419-3423.

(173) Vila, M. A.; Pazos, M.; Iglesias, C.; Veiga, N.; Seoane, G.; Carrera, I. Toluene Dioxygenase-Catalysed Oxidation of Benzyl Azide to Benzonitrile: Mechanistic Insights for an Unprecedented Enzymatic Transformation. ChemBioChem 2016, 17, 291-295.

(174) Goldberg, N. W.; Knight, A. M.; Zhang, R. K.; Arnold, F. H. Nitrene Transfer Catalyzed by a Non-Heme Iron Enzyme and Enhanced by Non-Native Small-Molecule Ligands. J. Am. Chem. Soc. 2019, 141, 19585-19588.

(175) Vila, M. A.; Steck, V.; Rodriguez Giordano, S.; Carrera, I.; Fasan, R. C-H Amination via Nitrene Transfer Catalyzed by Mononuclear Non-Heme Iron-Dependent Enzymes. ChemBioChem 2020, 21, 1981-1987.

(176) Hammer, S. C.; Knight, A. M.; Arnold, F. H. Design and Evolution of Enzymes for Non-Natural Chemistry. Curr. Opin. Green Sustain. Chem. 2017, 7, 23-30.

(177) Reetz, M. T.; Carballeira, J. D. Iterative Saturation Mutagenesis (ISM) for Rapid Directed Evolution of Functional Enzymes. Nat. Protoc. 2007, 2, 891-903.

(178) Renata, H.; Wang, Z. J.; Arnold, F. H. Expanding the Enzyme Universe: Accessing Non-Natural Reactions by Mechanism-Guided Directed Evolution. Angew. Chem. Int. Ed. 2015, $54,3351-3367$.

(179) Haines, D. C.; Tomchick, D. R.; Machius, M.; Peterson, J. A. Pivotal Role of Water in the Mechanism of P450BM-3. Biochemistry 2001, 40, 13456-13465.

(180) Lewis, R. D.; Garcia-Borràs, M.; Chalkley, M. J.; Buller, A. R.; Houk, K. N.; Kan, S. B. J.; Arnold, F. H. Catalytic Iron-Carbene Intermediate Revealed in a Cytochrome $c$ Carbene Transferase. Proc. Natl. Acad. Sci. U.S.A. 2018, 115, 7308-7313.

(181) Zhang, X.; Peng, Y.; Zhao, J.; Li, Q.; Yu, X.; Acevedo-Rocha, C. G.; Li, A. Bacterial Cytochrome P450-Catalyzed Regio- and Stereoselective Steroid Hydroxylation Enabled by Directed Evolution and Rational Design. Bioresour. Bioprocess. 2020, 7, 2.

(182) Li, R.-J.; Zhang, Z.; Acevedo-Rocha, C. G.; Zhao, J.; Li, A. Biosynthesis of Organic Molecules via Artificial Cascade Reactions Based on Cytochrome P450 Monooxygenases. Green Synth. Catal. 2020, 1, 52-59.

(183) Loskot, S. A.; Romney, D. K.; Arnold, F. H.; Stoltz, B. M. Enantioselective Total Synthesis of Nigelladine A via Late-Stage C-H Oxidation Enabled by an Engineered P450 Enzyme. J. Am. Chem. Soc. 2017, 139, 10196-10199. 
(184) Li, J.; Li, F.; King-Smith, E.; Renata, H. Merging Chemoenzymatic and RadicalBased Retrosynthetic Logic for Rapid and Modular Synthesis of Oxidized Meroterpenoids. Nat. Chem. 2020, 12, 173-179.

(185) Zhang, X.; King-Smith, E.; Renata, H. Total Synthesis of Tambromycin by Combining Chemocatalytic and Biocatalytic C-H Functionalization. Angew. Chem. Int. Ed. 2018, 57, 5037-5041.

(186) Zwick, C. R.; Renata, H. A One-Pot Chemoenzymatic Synthesis of $(2 S, 4 R)-4-$ Methylproline Enables the First Total Synthesis of Antiviral Lipopeptide Cavinafungin B. Tetrahedron 2018, 74, 6469-6473.

(187) Zwick, C. R.; Renata, H. Remote C-H Hydroxylation by an $\alpha$-KetoglutarateDependent Dioxygenase Enables Efficient Chemoenzymatic Synthesis of Manzacidin C and Proline Analogs. J. Am. Chem. Soc. 2018, 140, 1165-1169.

(188) Zhang, X.; Renata, H. Efficient chemoenzymatic synthesis of (2S,3R)-3-hydroxy3-methylproline, a key fragment in polyoxypeptin A and FR225659. Tetrahedron 2019, 75, 32533257.

(189) Hayashi, T.; Ligibel, M.; Sager, E.; Voss, M.; Hunziker, J.; Schroer, K.; Snajdrova, R.; Buller, R. Evolved Aliphatic Halogenases Enable Regiocomplementary C-H Functionalization of a Pharmaceutically Relevant Compound. Angew. Chem. Int. Ed. 2019, 58, 18535-18539.

(190) Zwick, C. R.; Sosa, M. B.; Renata, H. Characterization of a Citrulline 4Hydroxylase from Nonribosomal Peptide GE81112 Biosynthesis and Engineering of Its Substrate Specificity for the Chemoenzymatic Synthesis of Enduracididine. Angew. Chem. Int. Ed. 2019, 58, 18854-18858.

(191) Doyon, T. J.; Perkins, J. C.; Baker Dockrey, S. A.; Romero, E. O.; Skinner, K. C.; Zimmerman, P. M.; Narayan, A. R. H. Chemoenzymatic o-Quinone Methide Formation. J. Am. Chem. Soc. 2019, 141, 20269-20277.

(192) Duewel, S.; Schmermund, L.; Faber, T.; Harms, K.; Srinivasan, V.; Meggers, E.; Hoebenreich, S. Directed Evolution of an Fe $\mathrm{II}_{-}$-Dependent Halogenase for Asymmetric C $\left(s p^{3}\right)-\mathrm{H}$ Chlorination. ACS Catal. 2020, 10, 1272-1277.

(193) Zhang, X.; King-Smith, E.; Dong, L.-B.; Yang, L.-C.; Rudolf, J. D.; Shen, B.; Renata, H. Divergent Synthesis of Complex Diterpenes Through a Hybrid Oxidative Approach. Science 2020, 369, 799-806.

(194) Mailyan, A. K.; Chen, J. L.; Li, W.; Keller, A. A.; Sternisha, S. M.; Miller, B. G.; Zakarian, A. Short Total Synthesis of $\left[{ }^{15} \mathrm{~N}_{5}\right]$-Cylindrospermopsins from ${ }^{15} \mathrm{NH}_{4} \mathrm{Cl}$ Enables Precise Quantification of Freshwater Cyanobacterial Contamination. J. Am. Chem. Soc. 2018, 140, 60276032.

(195) Baker Dockrey, S. A.; Lukowski, A. L.; Becker, M. R.; Narayan, A. R. H. Biocatalytic Site- and Enantioselective Oxidative Dearomatization of Phenols. Nat. Chem. 2018, 10, 119-125.

(196) Wang, Z. J.; Renata, H.; Peck, N. E.; Farwell, C. C.; Coelho, P. S.; Arnold, F. H. Improved Cyclopropanation Activity of Histidine-Ligated Cytochrome P450 Enables the Enantioselective Formal Synthesis of Levomilnacipran. Angew. Chem. Int. Ed. 2014, 53, 68106813.

(197) Hernandez, K. E.; Renata, H.; Lewis, R. D.; Kan, S. B. J.; Zhang, C.; Forte, J.; Rozzell, D.; McIntosh, J. A.; Arnold, F. H. Highly Stereoselective Biocatalytic Synthesis of Key Cyclopropane Intermediate to Ticagrelor. ACS Catal. 2016, 6, 7810-7813. 
(198) Bajaj, P.; Sreenilayam, G.; Tyagi, V.; Fasan, R. Gram-Scale Synthesis of Chiral Cyclopropane-Containing Drugs and Drug Precursors with Engineered Myoglobin Catalysts Featuring Complementary Stereoselectivity. Angew. Chem. Int. Ed. 2016, 55, 16110-16114.

(199) Truppo, M. D. Biocatalysis in the Pharmaceutical Industry: The Need for Speed. ACS Med. Chem. Lett. 2017, 8, 476-480.

(200) Sheldon, R. A.; Woodley, J. M. Role of Biocatalysis in Sustainable Chemistry. Chem. Rev. 2018, 118, 801-838.

(201) Hauer, B. Embracing Nature's Catalysts: A Viewpoint on the Future of Biocatalysis. ACS Catal. 2020, 10, 8418-8427.

(202) Wu, S.; Snajdrova, R.; Moore, J. C.; Baldenius, K.; Bornscheuer, U. Biocatalysis: Enzymatic Synthesis for Industrial Applications. Angew. Chem. Int. Ed. 2020, 59, 2-34.

\section{TOC Graphic:}

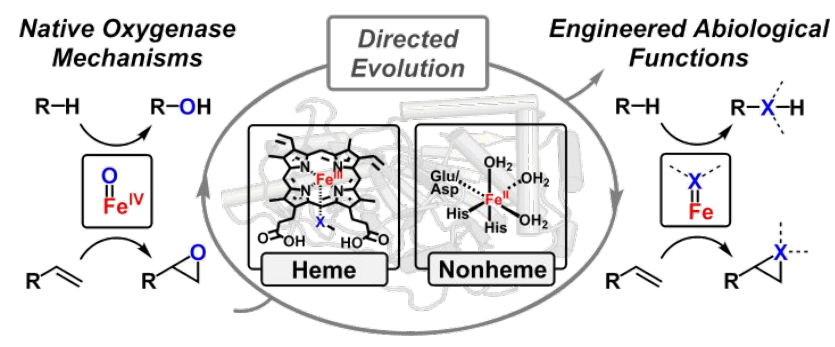

